\title{
Vagal Transient Receptor Potential Ankyrin 1 Mediates Stress-exacerbated Visceral Mechanonociception After Antral Cold Exposure
}

\author{
Xin Chen, Qingqing Luo, Xiujuan Yan, Wenting Li, and Shengliang Chen* \\ Division of Gastroenterology and Hepatology, Key Laboratory of Gastroenterology and Hepatology, Ministry of Health, Renji Hospital, School of \\ Medicine, Shanghai Jiao Tong University, Shanghai Institute of Digestive Disease, Shanghai, China
}

\section{Background/Aims}

Abdominal pain can be evoked or exacerbated after gastrointestinal cold stimulation in some patients with diarrhea-predominant irritable bowel syndrome (IBS-D), indicating a low temperature-induced sensitization of visceral perception. We investigated the role of vagal transient receptor potential ankyrin 1 (TRPA1, a cold-sensing ion channel) in cold-aggravated visceral mechanonociception in a stress-induced IBS animal model.

\section{Methods}

TRPA1 expression was examined in antral biopsies of healthy controls and IBS-D patients. Abdominal symptoms were assessed before and after warm or cold water intake. The visceromotor response (VMR) to colorectal distention (CRD) following intra-antral infusion of cold saline was measured in animals undergoing sham or chronic water avoidance stress. TRPA1 expression, extracellular signalregulated protein kinase 1/2 (ERK1/2) phosphorylation, and neuronal calcium influx in vagal afferents were assessed.

\section{Results}

Compared to healthy controls, IBS-D patients displayed elevated antral TRPA1 expression, which was associated with symptom scores after cold $\left(4^{\circ} \mathrm{C}\right)$ water intake. Intra-antral infusion of cold saline increased VMR to CRD in naive rats, an effect dependent on vagal afferents. In stressed rats, this effect was greatly enhanced. Functional blockade and gene deletion of TRPA1 abolished the cold effect on visceral nociception. TRPA1 expression in vagal (but not spinal) afferents increased after stress. Moreover, the cold-induced, TRPA1dependent ERK1/2 activation and calcium influx in nodose neurons were more robust in stressed rats.

\section{Conclusions}

Stress-exaggerated visceral mechanonociception after antral cold exposure may involve up-regulation of TRPA1 expression and function on vagal afferents. Our findings reveal a novel mechanism for abnormal gastrointestinal cold sensing in IBS.

(J Neurogastroenterol Motil 2019;25:442-460)

\section{Key Words}

Cold temperature; Stress, psychological; TRPA1 cation channel; Vagus nerve; Visceral pain

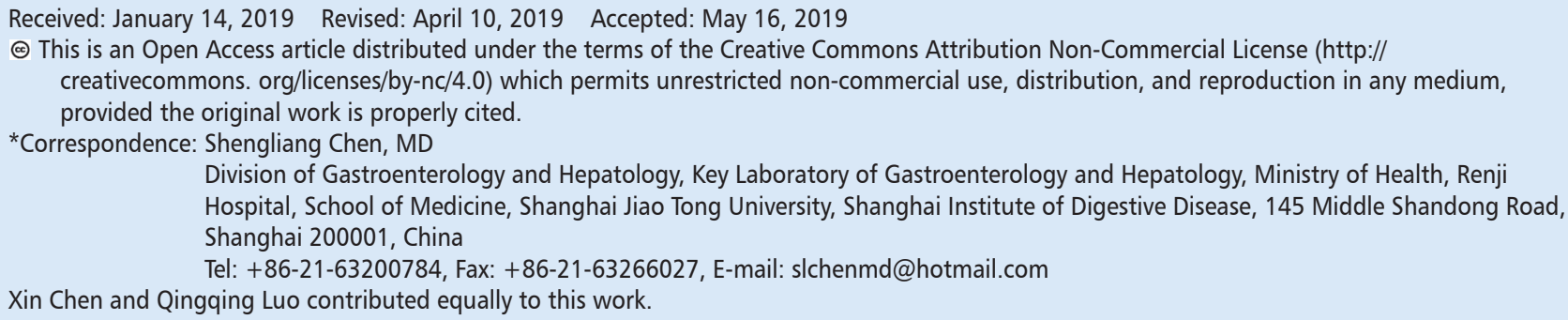




\section{Introduction}

Irritable bowel syndrome (IBS) is characterized by abdominal pain and changes in bowel habits in the absence of an organic cause. Although the pathogenesis is still not completely understood, visceral hypersensitivity appears to be a key factor. ${ }^{1}$ IBS symptoms such as abdominal pain are linked closely to the disturbance of brain-gut interactions (eg, psychological stress). ${ }^{2}$ In addition, biological factors in the gut, including mucosal inflammation, intestinal dysbiosis, and enteroendocrine signals arising in the mucosa, are also reported to contribute to the development of IBS symptoms. ${ }^{1}$ The upper gastrointestinal (GI) tract is often exposed to a cold environment. Consistent with our observations in clinical practice, several groups report that, different from the healthy subjects, some patients with functional GI disorders such as IBS exhibit aggravated abdominal pain after cold $\left(4-8^{\circ} \mathrm{C}\right)$ stimulation of the upper GI tract, ${ }^{3,4}$ indicating a low temperature-induced sensitization of visceral perception. However, the underlying mechanisms are not fully elucidated.

The peripheral endings of sensory nerves receive thermal inputs from a variety of temperature sensors, and the transient receptor potential (TRP) ion channels are the most important type. These channels include heat-sensitive TRP vanilloid 1 (TRPV1), cold-sensitive TRP ankyrin 1 (TRPA1), and TRP melastatin 8 (TRPM8). ${ }^{5}$ Mounting evidence shows that TRPA1 (threshold, approximately $17^{\circ} \mathrm{C}$ ) is a key sensor of noxious cold in somatic tissues and blood vessels. ${ }^{5-7}$ Besides, TRPA1 is critical for transducing irritant and inflammatory stimuli into nociceptor activities in primary sensory neurons. ${ }^{8,9}$

The gut is innervated by 2 sets of sensory fibers: the vagal afferents that project via the nodose ganglia to the nucleus of the solitary tract in the brainstem, and the spinal afferents that project via the dorsal root ganglia (DRG) to the spinal cord. The spinal afferents primarily process noxious information from the gut, whereas vagal afferents are thought to primarily convey physiological information. ${ }^{10}$ However, recent studies have demonstrated the role of vagal afferents in sensing noxious physical and chemical stimuli. ${ }^{11,12}$ Moreover, vagal afferents can drive a descending modulation (inhibition and potentiation) of visceral pain. ${ }^{10,13,14}$ Accumulating evidence shows that TRPA1 is expressed in the peripheral sensory neurons innervating the gut and plays an essential role in visceral nociception. ${ }^{15-19}$ Interestingly, we observed in a preliminary clinical study that the mRNA levels of TRPA1 in the antral mucosal biopsies from patients with diarrhea-predominant IBS (IBS-D) was elevated compared to healthy subjects, indicating a link between the cold-sensing TRPA1 channels in the upper GI tract and abnormal GI cold sensing in IBS. However, the details of this link are still largely unidentified.

In this study, we explored the relationship between antral TRPA1 mRNA levels and abdominal symptoms (including severity of abdominal pain/discomfort, bloating, and diarrhea) in a larger population of IBS-D patients and healthy control subjects. Also, using a stress-induced visceral hypersensitive animal model, we tested the hypothesis that vagal TRPA1 signaling is enhanced upon stress and that this enhanced signaling contributes to the exacerbation of visceral pain after gastric cold exposure.

\section{Materials and Methods}

\section{Human Subjects}

Nineteen symptomatic IBS-D patients, aged between 23 years and 69 years ( 8 men and 11 women) were recruited from the Gastroenterology and Hepatology Department of Renji Hospital. IBSD was diagnosed based on the Rome III criteria (with abdominal pain/discomfort [relief with defecation and with the frequency of at least 2 days a week during screening evaluation for the subject] within the recent 3 months and a stool frequency of $\geq 3 /$ day). Meanwhile, subjects underwent psychological assessments. The severity of anxiety and depression symptoms was assessed by the Hamilton Anxiety Scale (14 items version) $)^{20}$ and Hamilton Depression Scale (24 items version). ${ }^{21}$ Twenty-three healthy people, aged between 22 years and 69 years ( 11 men and 12 women) who had no recent history of gastroenteritis and other illness were enrolled as normal controls. All the enrolled subjects had no organic disorders, and they were asked to discontinue the use of any drugs that could affect the GI function and symptoms 1 week prior to study. Gastroscopy was performed under fasting conditions 3 days prior to cold exposure. Three mucosal samples were obtained from the lesser curvature side of the antrum of each subject with standard biopsy forceps. Two samples were immediately placed in liquid nitrogen and then stored at $-80^{\circ} \mathrm{C}$ for subsequent mRNA analysis, and another sample was fixed for histological analysis. The study was approved by the Ethics Committee of Renji Hospital (Approval No. 2015-003) and performed in accordance with the Declaration of Helsinki. Informed consent was obtained from all participants.

\section{Assessment of Abdominal Symptoms Before and After Intake of Cold Water}

Each individual fasted for at least 10 hours before intake of 
warm or cold water. The procedure of intake of warm or cold water was similar to that described in the previous studies with a mild modification. ${ }^{3}$ Before each drink, subjects were asked to report the severity of abdominal symptoms (abdominal pain/discomfort, bloating, and diarrhea). All subjects were asked to drink a bottle (220 $\mathrm{mL})$ of warm $\left(37^{\circ} \mathrm{C}\right)$ water within 10 seconds and allowed to rest 2 hours. Then they were asked to drink the same volume of cold $\left(4^{\circ} \mathrm{C}\right)$ water within 10 seconds. After each drink, subjects were asked to report the severity of abdominal symptoms during the 1-hour observation period with a questionnaire. The symptoms were graded as follows: abdominal pain/discomfort: 0 , absent; 1 , unable to be perceived unless being given some suggestions; 2 , obvious yet endurable; and 3, intense and unendurable. Bloating: 0, absent; 1, unable to be perceived unless being given some suggestions; 2, obvious yet endurable; and 3, intense and unendurable. Diarrhea: 0 , absent and 1 , diarrhea occurs. The total symptom score of each subject is the sum of individual symptom scores, which was assessed and summarized by an investigator blinded to this study.

\section{Animals}

Adult male Sprague-Dawley rats (200-250 g) were purchased from Shanghai Laboratory Animal Center, Chinese Academy of Science. TRPA1-knockout (KO; TRPA1 ${ }^{-/}$) mice were obtained from the Jackson Laboratory and were inbred through crossmating to obtain homozygous TRPA $1^{-/}$mice and the wild type littermates $\left(\mathrm{TRPA}^{+/+}\right)$. Genotyping was performed by polymerase chain reaction (PCR) from tail genomic DNA. Experiments were performed on male mice aged 10-12 weeks. The animals were housed in a temperature-controlled room $\left(22-24^{\circ} \mathrm{C}\right)$ on a normal light-dark cycle, with free access to food and water. All experimental protocols met the National Institutes of Health Guide for the Care and Use of Laboratory Animals and were approved by the Institutional Animal Care and Use Committee (IACUC) of the School of Medicine, Shanghai Jiao Tong University (Approval No. B-2018004).

\section{Implantation of Electrodes and Intra-antral Cannulas}

Rats or mice were anesthetized with sodium pentobarbital (45 $\mathrm{mg} / \mathrm{kg}$; intraperitoneal [ip]). Electromyogram (EMG) electrodes made from Teflon-coated, 32-gauge stainless steel wires were inserted into the abdominal external oblique muscles. The lead wires were tunneled subcutaneously and exteriorized at the back of the neck. A polyethylene tube (outer diameter, $0.9 \mathrm{~mm}$; Shanghai Industrial Ceramics Electrical Co, Ltd, Shanghai, China) was gently inserted into the gastric antrum (positioned at $0.5-1 \mathrm{~cm}$ [for rats] and 0.3$0.5 \mathrm{~cm}$ [for mice] away from the pylorus) from the gastric fundus for infusion of cold or warm saline. The cannula was fixed with sutures, and its remaining free end was exteriorized at the back of the neck. After completion of testing, the positions of the electrodes and cannulas were verified in each animal by post-mortem examination. The experimental data of animals with wrong positions were excluded. After surgery, the animals were given ip injection of penicillin (no postoperative analgesics were used) and were allowed to recover for 3-5 days.

\section{Antral Cold Stimulation}

For antral cold stimulation, cold saline $\left(\right.$ at $0{ }^{\circ} \mathrm{C}, 4^{\circ} \mathrm{C}$, or $8^{\circ} \mathrm{C} ; 0.5$ $\mathrm{mL}$ ) was rapidly (within 10 seconds) perfused into the gastric antrum of rats using a syringe through the exteriorized cannulas. The control animals received warm saline $\left(37^{\circ} \mathrm{C}\right)$ infusion. For mice, the volume of cold water for antral infusion was $0.2 \mathrm{~mL}$.

\section{Assessment of Visceromotor Response to Colorectal Distension}

Rats or mice were mildly sedated with ether inhalation. A flexible latex balloon (for rats: $4-5 \mathrm{~cm}$ long; for mice: $1.5 \mathrm{~cm}$ long) with a catheter fixed at the tail was gently inserted into the descending colon and rectum such that its end was $1 \mathrm{~cm}$ proximal to the anus. CRD was produced by inflating the distension balloon with air. The pressure was regulated with a distention control device and monitored using a pressure transducer. VMR was assessed by measurement of EMG activity in the external oblique muscles in response to graded CRD pressures (for rats: 20, 40, and $60 \mathrm{mmHg}$; for mice: 15, 30, 45, and $60 \mathrm{mmHg}$ ). Each distention lasted for $20 \mathrm{sec}-$ onds and was tested 3 times with a 3-minute inter-stimulus interval. The EMG recordings were collected and analyzed with Chart 7.5 for Windows (AD Instruments, Bella Vista, NSW, Australia), and were quantified by calculating the area under the curve (10 seconds) during distention after subtraction of predistention values.

\section{Perivagal Application of Capsaicin}

Under anesthesia with sodium pentobarbital, the abdominal vagal nerve trunks of rats were exposed and isolated. A cotton ball soaked in capsaicin $(1 \mathrm{mg} / \mathrm{mL}$; Sigma-Aldrich, St. Louis, MO, USA) was placed around the vagal trunks for 30 minutes. Animals in the control group received vehicle (10\% Tween 80 in olive oil). The VMR to CRD was assessed 5 days later. 


\section{Water Avoidance Stress}

Repeated water avoidance stress (WAS) was conducted with rats as described previously. ${ }^{22}$ The rats were placed on a glass platform $(10 \mathrm{~cm} \times 8 \mathrm{~cm} \times 8 \mathrm{~cm})$ in the middle of a test Plexiglas tank $(45 \mathrm{~cm} \times 25 \mathrm{~cm} \times 25 \mathrm{~cm})$ that was filled with water $\left(25^{\circ} \mathrm{C}\right)$ to 1 $\mathrm{cm}$ below the platform. The animals were maintained on the block for 1 hour daily for 10 consecutive days. The sham control rats were placed similarly on the platform for 10 days in a waterless container.

For mice, WAS was conducted for 1 hour daily for 9 consecutive days as described previously. ${ }^{23}$ Mice were placed on a platform (4-cm diameter) in a bucket of water (28-cm diameter) for 1 hour each day, standing $1 \mathrm{~cm}$ above the water level and $23 \mathrm{~cm}$ below the brim of the bucket. Control mice were handled but were not exposed to the stress.

\section{Pain Behavioral Experiments}

In an experiment with naive rats, cold saline was delivered by intra-antral infusion. Rats in the control group were infused with warm $\left(37^{\circ} \mathrm{C}\right)$ saline. In another experiment, cold or warm saline was infused to rats previously subjected to a 10-day WAS or sham stress. The VMR to CRD was assessed 15 minutes after termination of infusion.

To examine the effect of TRPA1 inhibitors on cold-induced responses, A-967079 (dissolved in 50\% dimethyl sulfoxide [DMSO]; Sigma-Aldrich) was ip (6 mg/kg) or intra-antrally (6 $\mu \mathrm{g} / \mathrm{mL})$ and HC-030031 (1 mg/mL in 10\% DMSO; Sigma-Aldrich) was intra-antrally administered to rats 15 minutes before infusion of cold saline. The control group received vehicle and warm saline infusion. In a separate study, a TRPA1 agonist cinnamaldehyde $(1.2 \mathrm{mg} / \mathrm{mL}$ in $10 \%$ DMSO; Sigma-Aldrich) or a TRPM8 agonist L-menthol (4 mg/mL in 10\% ethanol; Sigma-Aldrich) was delivered intra-antrally 20 minutes prior to VMR assessment. The doses of the agonists and antagonists were selected based on previous reports. $^{18,24-27}$

To explore the effect of TRPA1 deletion on cold-induced responses under stressful conditions, TRPA $1^{-/}$mice and TRPA $1^{+/+}$ littermates were subjected to a 9-day WAS. On day 10, cold saline was intra-antrally infused and the VMR to CRD was evaluated.

\section{Immunohistochemistry}

Human antral mucosal samples were fixed with $4 \%$ paraformaldehyde for 24 hours and were sectioned. Rats were given an overdose of sodium pentobarbital 10 minutes (for phosphoextracellular signal-regulated protein kinase $1 / 2$ [p-ERK1/2]) or 2 hours (for FBJ osteosarcoma cellular oncogene [c-Fos], which is a marker for neuronal activity) after infusion of warm or cold saline. The animals were transcardially perfused with $4 \%$ paraformaldehyde. Nodose ganglia and thoracic (T6-10) DRG were removed, fixed with $4 \%$ paraformaldehyde for 24 hours, and paraffin-embedded and sectioned. The sections $(4 \mu \mathrm{m})$ of human antrum were incubated with rabbit anti-TRPA1 (GTX54765; GeneTex, Irvine, CA, USA), and the sections of rat tissues were incubated with rabbit anti-p-ERK1/2 (Catalog No. 9101; Cell Signaling Technology, Beverly, MA, USA) or rabbit anti-c-Fos (ab102699; 1:200; Abcam, Cambridge, MA, USA) antibody overnight at $4{ }^{\circ} \mathrm{C}$. They were then incubated with goat anti-rabbit horseradish peroxidaseconjugated secondary antibody (Invitrogen, Carlsbad, CA, USA) for 30 minutes at room temperature and were visualized with a diaminobenzidine-enhanced liquid substrate system (Sigma-Aldrich). For double-immunofluorescence staining, the sections of rat nodose ganglia were incubated with rabbit anti-TRPA1 (ab58844; Abcam) or anti-TRPM8 (ab74845; Abcam) and mouse anti-pERK1/2 (Catalog No. 5726; Cell Signaling Technology) antibodies overnight at $4{ }^{\circ} \mathrm{C}$, followed by incubation with secondary antibodies raised in donkey coupled to Alexa Fluor 488 or Alexa Fluor 546 (1:500; Invitrogen) for 1 hour at room temperature for visualization. Negative controls were prepared as above with the primary antibody omitted. Details of the primary antibodies were presented in Supplementary Table 1. The images were captured under a confocal microscope (LSM-710; Zeiss, Jena, TH, Germany).

\section{Quantitative Real-time Polymerase Chain Reaction}

Total RNA was isolated from the antral mucosal biopsies of IBS-D patients and healthy controls and the antral tissues and T610 DRG of stressed- or sham stressed-rats with an EZNA Total RNA Kit (Omega Bio-tek, Doraville, GA, USA) according to the manufacturer's instructions. One microgram of total RNA was reverse transcribed into cDNA using the PrimeScript RT reagent Kit (Takara, Otsu, Shiga, Japan). Quantitative PCR was performed by a StepOnePlus real-time PCR system (Applied Biosystems, Foster City, CA, USA) using a SYBR Premix Ex Taq Kit (Takara). Glyceraldehyde-3-phosphate dehydrogenase (GAPDH) was used as a reference. The primer sequences were shown in Table 1 . The relative amount of mRNA transcript was determined by $2^{-\Delta \mathrm{Ct}}$ calculation.

\section{Western Blot}

The pooled nodose ganglia were homogenized in lysis buffer (50 $\mathrm{mM}$ Tris- $\mathrm{HCl}$ [pH 7.4], 150 mM NaCl, 1 mM EDTA, $1 \%$ Triton $\mathrm{X}-100,1 \%$ sodium deoxycholate, $0.1 \%$ sodium dodecyl sulfate 
Table 1. Sequences for the Designed Primers Used in Quantitative Polymerase Chain Reaction Experiments

\begin{tabular}{|c|c|c|c|c|}
\hline Species & Gene & ID & Forward primer (5'-3') & Reverse primer (5'-3') \\
\hline \multirow[t]{3}{*}{ Human } & TRPA1 & 8989 & GAGAGTCCTTCCTAGAACCATATCTGA & GAGAGTCCTTCCTAGAACCATATCTGA \\
\hline & TRPM8 & 79054 & ACTCAGAAGGCTGAGGTACA & TTCAGTCGGAGTCTCACTCT \\
\hline & GAPDH & 2597 & CTGGGCTACACTGAGCACC & AAGTGGTCGTTGAGGGCAA \\
\hline \multirow[t]{9}{*}{ Rat } & $\mathrm{TRPA}^{28}$ & 312896 & TGCTGAGATCGACGGGAGTG & GGGTATGCCAACTCATTCCTGAAC \\
\hline & $\mathrm{TRPV}^{29}$ & 83810 & TCATGGGTGAGACCGTCAACAAG & TCCTTGCCGTCAGGAGTGAA \\
\hline & TNF- $\alpha$ & 24835 & CCCAATCTGTGTCCTTCTA & GCTATCCCCATCTGGTCCCC \\
\hline & IL-1 $\beta$ & 24494 & CTGTGACTCGTGGGATGATG & GGGATTTTGTCGTTGCTTGT \\
\hline & IL-17 & 301289 & TCACAGTTGAATCTCAGCAA & TTTTAAATTATTGAGGCT \\
\hline & IL-6 & 24498 & CCGGAGAGGAGACTTCACAG & ACAGTGCATCATCGCTGTTC \\
\hline & iNOS & 24599 & CCCAGACCCTCACACTCAGAT & GTCCAAGAGAAGTTCCCTGTT \\
\hline & NGF & 310738 & TAGCGTAATGTCCATGTTGT & CCACACACTGACACTGTCA \\
\hline & GAPDH & 24383 & GTCTTCACTACCATGGAGAA & TCATGGATGACCTTGGCC \\
\hline
\end{tabular}

TRPA1, transient receptor potential ankyrin 1; TRPM8, transient receptor potential melastatin 8; GAPDH, glyceraldehyde-3-phosphate dehydrogenase; TRPV1, transient receptor potential vanilloid 1 ; TNF- $\alpha$, tumor necrosis factor- $\alpha$; IL, interleukin; iNOS, inducible nitric oxide synthase; NGF, nerve growth factor.

[SDS], and $1 \mathrm{mM} \mathrm{Na}_{3} \mathrm{VO}_{4}$ ) containing protease inhibitor cocktail (Sigma-Aldrich). Equal amounts of protein $(30 \mu \mathrm{g})$ were loaded and separated on an $8 \%$ SDS-PAGE gel and transferred to polyvinylidene difluoride membranes. Membranes were incubated with $5 \%$ skim milk and then with primary antibodies against TRPA1 (GTX54765, 1:200; GeneTex) or GAPDH (1:5000; Abcam) at ${ }^{\circ} \mathrm{C}$ overnight. They were then incubated with a horseradish peroxidase-conjugated secondary antibody (1:5000; Abcam) for 1 hour. The bands were visualized using enhanced chemiluminescence (Pierce, Rockford, IL, USA). Band density was quantified using Image J software.

\section{Isolation and Culture of Nodose Ganglia Neurons}

The nodose ganglia were excised from anesthetized rats and placed in ice-cold $\mathrm{Ca}^{2+}$ - and $\mathrm{Mg}^{2+}$-free Hank's balanced salt solution (Gibco, Grand Island, NY, USA) supplemented with penicillin and streptomycin $(100 \mathrm{U} / \mathrm{mL}$ and $100 \mu \mathrm{g} / \mathrm{mL}$, respectively; Gibco). The ganglia were cleaned of connective tissue and desheathed, and then were enzymatically dissociated by incubation in HEPES-buffered DMEM/F-12 (DMEM/F-12; Gibco) containing collagenase Ia (1 mg/mL; Sigma-Aldrich), dispase II (1 mg/mL; Sigma-Aldrich), and DNase I (100 U/mL; SigmaAldrich) at $37^{\circ} \mathrm{C}$ for 40 minutes. Thereafter, they were mechanically dissociated by passing 5-10 times through a fire-polished glass Pasteur pipette before separation with a Percoll PLUS (Sigma-Aldrich) density gradient. Individual cells were harvested by centrifugation at $700 \times \mathrm{g}$ for 3 minutes. They were then plated onto coverslips precoated with poly-L-lysine (Sigma-Aldrich) and were incubated overnight at $37^{\circ} \mathrm{C}$ in DMEM/F-12 with $10 \%$ fetal bovine serum
(Gibco) and antibiotics in a humidified $5 \% \mathrm{CO}_{2}$ atmosphere.

\section{Calcium Imaging}

Experiments were performed within 24 hours after plating of nodose neurons on coverslips (Warner Instruments, Hamden, CT, USA). Neurons were loaded with calcium indicator Fluo-4 AM $(2.5 \mu \mathrm{M})$ combined with $0.02 \%$ Pluronic F-127 (Molecular Probes, Waltham, MA, USA) in dark at $37^{\circ} \mathrm{C}$ for 30 minutes. Coverslips were then mounted onto a recording/perfusion chamber (RC-26G, Warner Instruments) and continuously perfused with DMEM/F-12 warmed at 35-36 $\mathrm{C}$. Fluo-4 fluorescence was recorded at $488 / 525 \mathrm{~nm}(\lambda \mathrm{ex} / \lambda \mathrm{em})$ for 5 minutes. Basal fluorescence was recorded for 1 minute before calcium ions $\left(\mathrm{Ca}^{2+}\right)$ entry was elicited by cold stimulation (the bath temperature was adjusted to about $12^{\circ} \mathrm{C}$ by perfusing with culture medium at $0^{\circ} \mathrm{C}$ ). A single stimulation was performed per coverslip. Results were expressed as the ratio between the basal and the maximum fluorescence during stimulation $(\mathrm{F} / \mathrm{F} 0)$.

\section{Statistical Methods}

All data are expressed as the mean \pm SEM. For clinical study, Student's $t$ test was used to analysis antral TRPA1 expression (unpaired) and symptom scores before and after drinking cold or warm water (paired). For animal experiments, the raw CRD-evoked VMR were normalized as a percentage of baseline level for the highest pressure $(60 \mathrm{mmHg})$ for each animal. Differences between experimental groups were performed using unpaired Student's $t$ test and one-way or repeated measures 2-way ANOVA followed by Bonferroni post-test. Significance was defined as $P<0.05$. 


\section{Results}

\section{Transient Receptor Potential Ankyrin 1 Expression in the Antral Mucosa of Patients With Diarrhea- predominant Irritable Bowel Syndrome}

The demographic and clinical characteristics of human subjects were shown in Table 2. No significant differences in age, gender, and body mass index were detected between patients and healthy controls. The duration of disease in IBS-D patients ranged from 0.5 years to 10 years and total symptom scores ranged from 3 to 6 . The scores of anxiety and depression were significantly higher in patients compared to controls $(P<0.001)$.

We first evaluated TRPA1 mRNA expression in antral mucosa specimens. The mean value of healthy controls was used as a refer- ence value. The relative TRPA1 mRNA level $(2.96 \pm 0.45)$ in the IBS-D group was significantly higher than that of controls $(P$ $<0.01$; Fig. 1A). There was no significant difference in TRPA1

Table 2. Demographic and Clinical Characteristics of Diarrhea-predominant Irritable Bowel Syndrome Patients and Healthy Controls

\begin{tabular}{|c|c|c|c|}
\hline Features & $\begin{array}{c}\text { IBS-D } \\
(\mathrm{n}=19)\end{array}$ & $\begin{array}{l}\text { Controls } \\
(\mathrm{n}=23)\end{array}$ & $P$-value \\
\hline Age (yr) & $54.9 \pm 2.8$ & $49.4 \pm 2.6$ & 0.158 \\
\hline Gender (male:female) & $8: 11$ & $11: 12$ & 0.711 \\
\hline Body mass index $\left(\mathrm{kg} / \mathrm{m}^{2}\right)$ & $21.8 \pm 0.4$ & $21.5 \pm 0.3$ & 0.516 \\
\hline Duration of disease & $3.2 \pm 0.5$ & - & - \\
\hline Total symptom score & $3.5 \pm 0.2$ & - & - \\
\hline Hamilton Anxiety Scale & $15.6 \pm 1.6$ & $4.1 \pm 0.7$ & $<0.001$ \\
\hline Hamilton Depression Scale & $14.0 \pm 1.4$ & $3.9 \pm 0.6$ & $<0.001$ \\
\hline
\end{tabular}

IBS-D, diarrhea-predominant irritable bowel syndrome.

Data are presented as mean \pm SEM

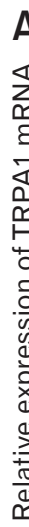

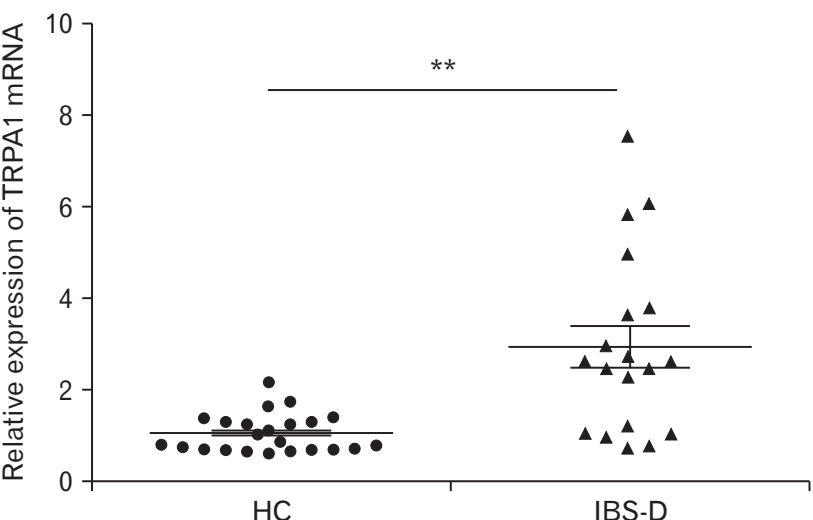

C
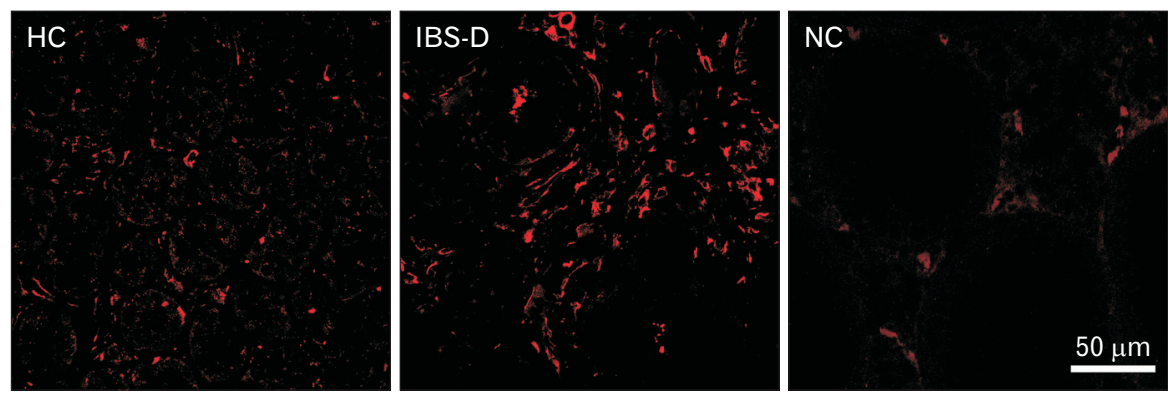

B

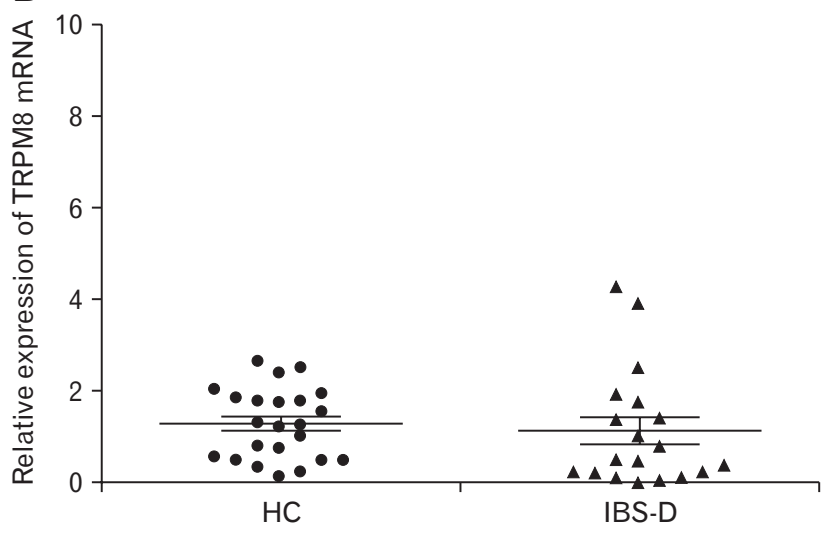

D

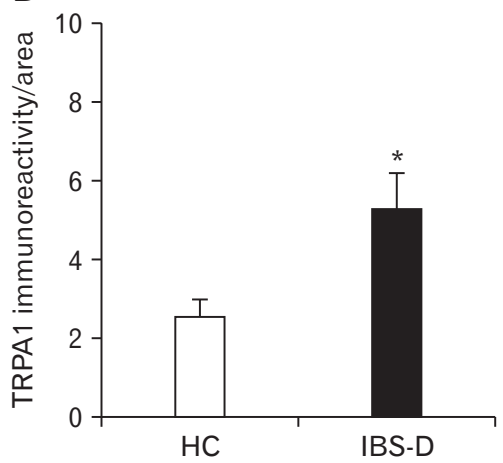

Figure 1. Transient receptor potential ankyrin 1 (TRPA1) expression in the antral mucosa of patients with diarrhea-predominant irritable bowel syndrome (IBS-D) is elevated. TRPA1 (A) and transient receptor potential melastatin 8 (TRPM8) (B) mRNA expression in antral mucosal biopsies from healthy controls (HC; $n=23)$ and patients with IBS-D $(n=19)$. (C) Representative photomicrographs showing TRPA1 immunoreactivity in the antral mucosa of a healthy control (left) and a patient with IBS-D (middle). The sections incubated with PBS instead of the primary antibody served as the negative control (NC; right). (D) Quantification of TRPA1 immunoreactivity using Image J software. ${ }^{\star} P<0.05,{ }^{* *} P<0.01$ (Student's $t$ test). 
mRNA levels between male and female patients (data not shown). The relative TRPM8 mRNA level $(1.16 \pm 0.29)$ in antral mucosa specimens of IBS-D group was not significantly different from that of controls $(P=0.638$; Fig. 1B). Immunofluorescent staining revealed that TRPA1-immunoreactivity within the antral mucosa of IBS-D patients was higher than that of controls $(P<0.05$; Fig. $1 \mathrm{C}$ and 1D).

\section{Abdominal Symptoms After Intake of Cold Water in Diarrhea-predominant Irritable Bowel Syndrome Patients}

Following warm water intake, no subjects in the healthy group reported any abdominal symptoms. The mean abdominal symptom score of IBS-D patients was unaltered after warm water intake (Fig. $2 \mathrm{~A})$. Following cold $\left(4^{\circ} \mathrm{C}\right)$ water intake, 13 of 19 IBS-Dpatients
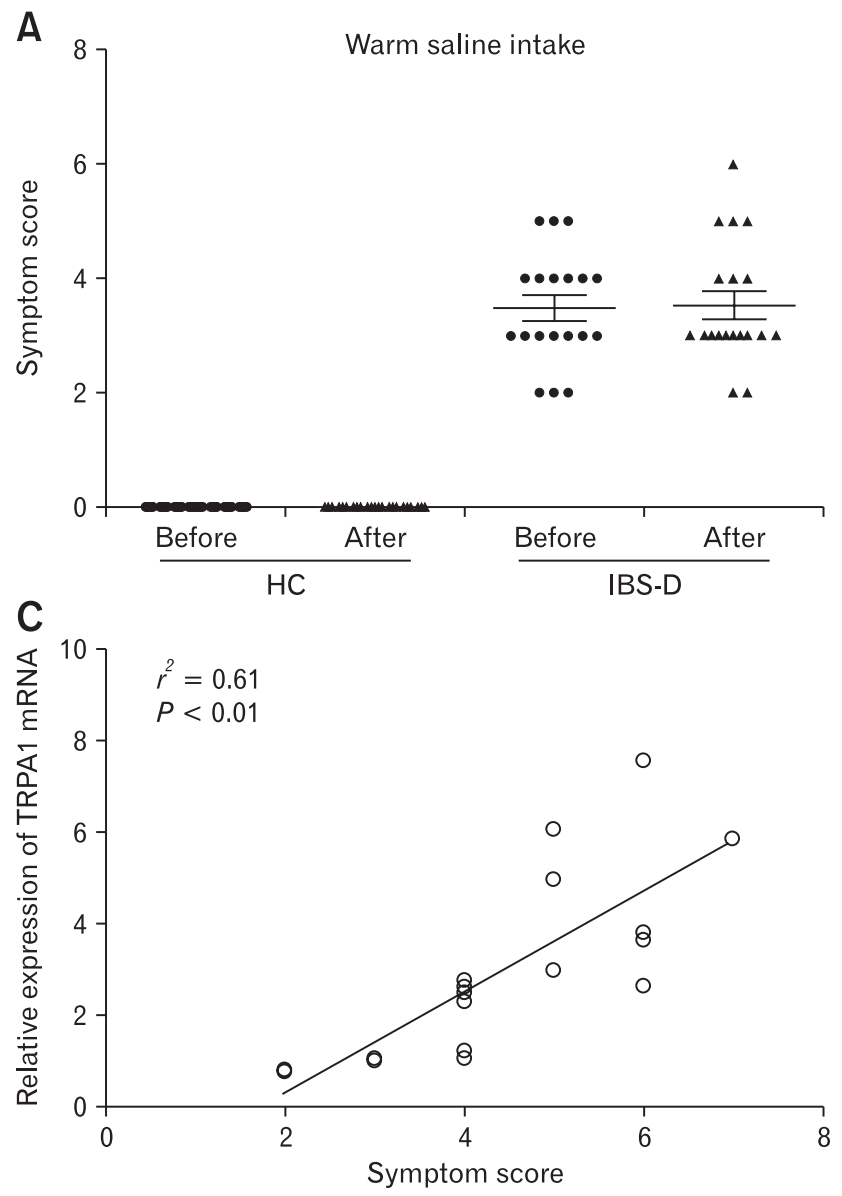

complained of aggravation of abdominal symptoms. Only 2 of 23 healthy controls reported mild bloating. In contrast to heathy controls, the mean abdominal symptom score after cold water intake in IBS-D group was significantly higher than that before cold water intake $(P<0.01$; Fig. $2 \mathrm{~B})$. We next analyzed the association between TRPA1 mRNA levels in the antral mucosa and abdominal symptoms after intake of cold water in IBS-D patients. Spearman correlation test revealed that antral mucosal TRPA1 mRNA levels positively correlated with abdominal symptom scores following cold water intake in IBS-D patients $(P<0.01$; Fig. 2 C).

\section{The Pronociceptive Effect Induced by Antral Cold Stimulation Involves Capsaicin-sensitive Vagal Afferents}

We then used VMR to CRD in rats as a model system to in-

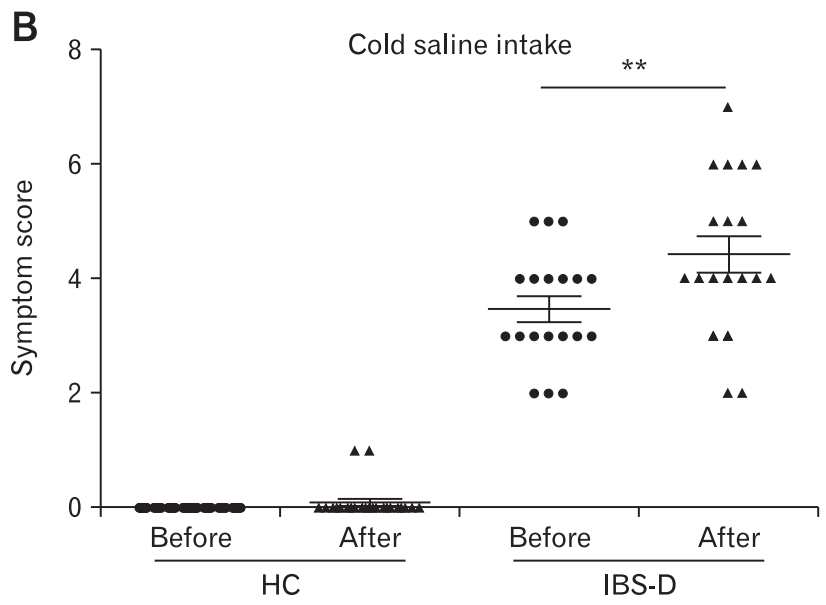

Figure 2. Transient receptor potential ankyrin 1 (TRPA1) mRNA levels in the antral mucosa correlates with abdominal symptoms after cold water intake in diarrhea-predominant irritable bowel syndrome (IBS-D) patients. Abdominal symptom scores before and after warm (A) and cold $\left(4^{\circ} \mathrm{C}\right.$; B) water intake in heathy controls and IBS-D patients. ${ }^{* *} P<0.01$ (Paired Student's $t$ test). (C) Correlation between antral TRPA1 mRNA levels and abdominal symptom scores after intake of cold water in IBS-D patients. HC, healthy controls. 

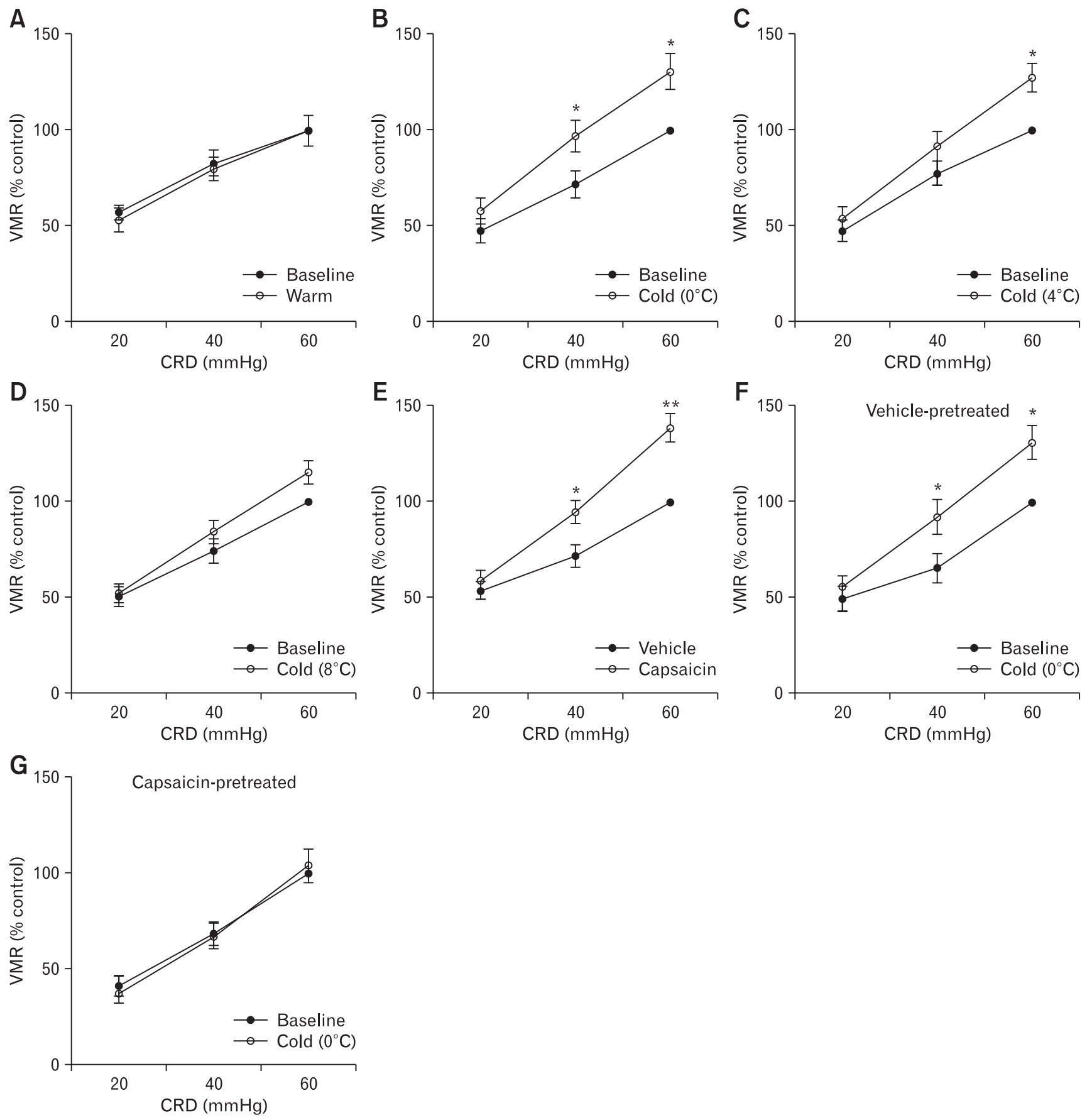

Figure 3. Cold-induced pronociception involves capsaicin-sensitive vagal afferents. (A) The visceromotor response (VMR) to colorectal distention $(\mathrm{CRD})$ after intra-antral infusion of warm $\left(37^{\circ} \mathrm{C}\right)$ saline $(0.5 \mathrm{~mL})$ in rats $(\mathrm{n}=6)$. (B-D) Effect of intra-antral infusion of saline at $0^{\circ} \mathrm{C}, 4^{\circ} \mathrm{C}$ or $8^{\circ} \mathrm{C}$ on the VMR to CRD $(n=6)$. (E) Effect of perivagal application of capsaicin on VMR to CRD in rats $(n=6)$. (F, G) Effect of intra-antral infusion of saline at $0^{\circ} \mathrm{C}$ on the VMR magnitude in rats previously subjected to perivagal application of vehicle or capsaicin $(\mathrm{n}=6)$. Data are expressed as mean $\pm \mathrm{SEM}$ of VMR expressed as $\%$ of $60 \mathrm{mmHg}$ response in the baseline set of $\mathrm{CRD}$. ${ }^{*} P<0.05$, ${ }^{*} P<0.01(2$-way ANOVA followed by Bonferroni post-test comparisons). 
vestigate the role of TRPA1 in the sensation of visceral nociception after antral cold exposure. The rats receiving intra-antral infusion of warm $\left(37^{\circ} \mathrm{C}\right)$ saline showed a similar VMR to $\mathrm{CRD}$ compared to baseline, while infusion of saline at $0^{\circ} \mathrm{C}$ induced a significant increase in the VMR magnitude at CRD pressures of $40 \mathrm{mmHg}$ and $60 \mathrm{mmHg}$ compared to baseline measurement (by $35.7 \pm$ $5.4 \%$ and $32.1 \pm 6.5 \%$ relative to baseline level for pressures of $40 \mathrm{mmHg}$ and $60 \mathrm{mmHg}$, respectively; $P<0.05$; Fig. $3 \mathrm{~A}$ and 3B). Intra-antral infusion of saline at $4^{\circ} \mathrm{C}$ induced an increase in the VMR to CRD at $60 \mathrm{mmHg}$ pressure compared to baseline (by $27.4 \pm 5.6 \%, P<0.05 ;$ Fig. $3 \mathrm{C}$ ). Infusion of saline at $8^{\circ} \mathrm{C}$ did not induce a remarkable increase in the VMR magnitude compared to baseline (Fig. 3D).

Additionally, infusion of cold saline led to increased c-Fos (a marker for neuronal activity) expression in nodose neurons $(P<$ 0.01 vs warm saline treatment; Supplementary Fig. 1), while c-Fos expression in DRG neurons after infusion of cold saline showed no difference from that after warm saline infusion (Supplementary Fig. 2). These results indicate that cold exposure stimulates vagal afferent activity. Then the animals were treated with perivagal capsaicin to functionally obliterate vagal afferents and were then assessed for the pain response to $\mathrm{CRD}$ after cold saline infusion. Treatment with capsaicin induced a greater CRD-evoked VMR at $40 \mathrm{mmHg}(P$ $<0.05)$ and $60 \mathrm{mmHg}$ compared to vehicle treatment $(P<0.01$; Fig. $3 \mathrm{E})$. In vehicle-pretreated rats intra-antral cold stimulation evoked a significantly increased VMR to CRD at pressures of 40 $\mathrm{mmHg}$ and $60 \mathrm{mmHg}$ compared to baseline (VMR measurement before saline infusion) $(P<0.05$; Fig. $3 \mathrm{~F})$, while in rats pretreated with capsaicin infusion of cold saline failed to elicit remarkable changes in VMR magnitude (Fig. 3G). These results suggest that the increased VMR to CRD after intra-antral infusion of cold saline depends on vagal (but not spinal) afferents.

\section{Cold-induced Pronociception Is Exacerbated in Rats Subjected to Chronic Stress}

Next, we tested whether antral cold exposure had an effect on CRD-evoked VMR in rats previously subjected to a 10-day WAS, a validated visceral hypersensitive animal model..$^{22}$ The VMR to graded CRD was recorded on day 0 before the start of WAS and was termed baseline day 0 . On day 11 , the VMR was recorded again before infusion of cold saline (to examine if WAS caused visceral hypersensitivity) and was termed baseline day 11 (served as baseline data for evaluation of the pronociceptive effect of antral cold stimulation). In contrast to the sham stress group, the CRDevoked VMR at pressures of $40 \mathrm{mmHg}$ and $60 \mathrm{mmHg}$ on day
11 in rats subjected to 10 -day WAS was significantly increased compared to baseline day $0(P<0.05$ at $40 \mathrm{mmHg}, P<0.01$ at $60 \mathrm{mmHg}$; Fig. 4A and 4B), indicating an induction of visceral hypersensitivity. In rats previously subjected to a 10-day sham stress, intra-antral infusion of saline at $0^{\circ} \mathrm{C}$ caused significantly increased VMR to CRD at pressures of $40 \mathrm{mmHg}$ and $60 \mathrm{mmHg}$ compared to baseline $\mathrm{d} 11$ (by $31.1 \pm 5.9 \%$ and $32.2 \pm 7.0 \%$ relative to baseline day 11 levels for pressures of $40 \mathrm{mmHg}$ and $60 \mathrm{mmHg}$, respectively; $P<0.05$; Fig. $4 \mathrm{C}$ ). In rats previously subjected to a 10-day WAS a more pronounced increase in the VMR magnitude to CRD at pressures of 20,40 , and $60 \mathrm{mmHg}$ was observed after intra-antral infusion of cold saline compared to baseline day 11 (by $48.4 \pm 6.6 \%, 52.9 \pm 9.9 \%$, and $66.2 \pm 12.3 \%$ relative to baseline day 11 levels for pressures of 20,40, and $60 \mathrm{mmHg}$, respectively; $P$ $<0.05$ at $20 \mathrm{mmHg}, P<0.01$ at $40 \mathrm{mmHg}$ and $60 \mathrm{mmHg}$; Fig. 4D; Supplementary Fig. 3), indicating an exaggerated antral cold sensing under stress conditions.

We also examined the VMR to CRD after infusion of saline at $4^{\circ} \mathrm{C}$ and $8^{\circ} \mathrm{C}$. In rats previously subjected to 10 -day sham stress, intra-antral infusion of saline at $4^{\circ} \mathrm{C}$ only elicited a remarkable increase in the VMR to CRD at $60 \mathrm{mmHg}$ (by $28.2 \pm 5.9 \%$ relative to baseline day 11 level, $P<0.05$; Fig. 4E). In rats previously undergoing a 10-day WAS, this effect was enhanced: intra-antral infusion of saline at $4^{\circ} \mathrm{C}$ caused a more pronounced increase in VMR to $\mathrm{CRD}$ at $40 \mathrm{mmHg}$ and $60 \mathrm{mmHg}$ pressures compared to baseline day 11 (by $42.6 \pm 6.7 \%$ relative to baseline day 11 level for pressure of $40 \mathrm{mmHg}, P<0.05$ and $50.2 \pm 6.4 \%$ relative to baseline day 11 level for pressure of $60 \mathrm{mmHg}, P<0.01$; Fig. $4 \mathrm{~F}$ ). In rats previously subjected to a 10 -day sham stress intra-antral infusion of saline at $8^{\circ} \mathrm{C}$ did not elicit a remarkable increase in the VMR to $\mathrm{CRD}$, whereas, in rats previously subjected to a 10-day WAS it caused a significant increase in VMR level compared to baseline day 11 at $60 \mathrm{mmHg}$ pressure (by $28.4 \pm 6.5 \%, P<0.05$; Fig. $4 \mathrm{G}$ and $4 \mathrm{H})$.

\section{Exacerbation of Cold-induced Pronociception by Chronic Stress Requires Transient Receptor Potential Ankyrin 1}

We first investigated whether TRPA1 is required in coldinduced sensitization of visceral pain in naive rats. In rats pretreated with vehicle, intra-antral infusion of cold saline caused significantly increased VMR to CRD compared to the baseline measurement ( $P$ $<0.05$ at $40 \mathrm{mmHg}$ and $60 \mathrm{mmHg}$ pressures; Fig. 5A and 5C). By contrast, in rats pretreated with systemically or intra-antrally delivered TRPA1 inhibitors (A-967079 and HC-030031), the VMR 

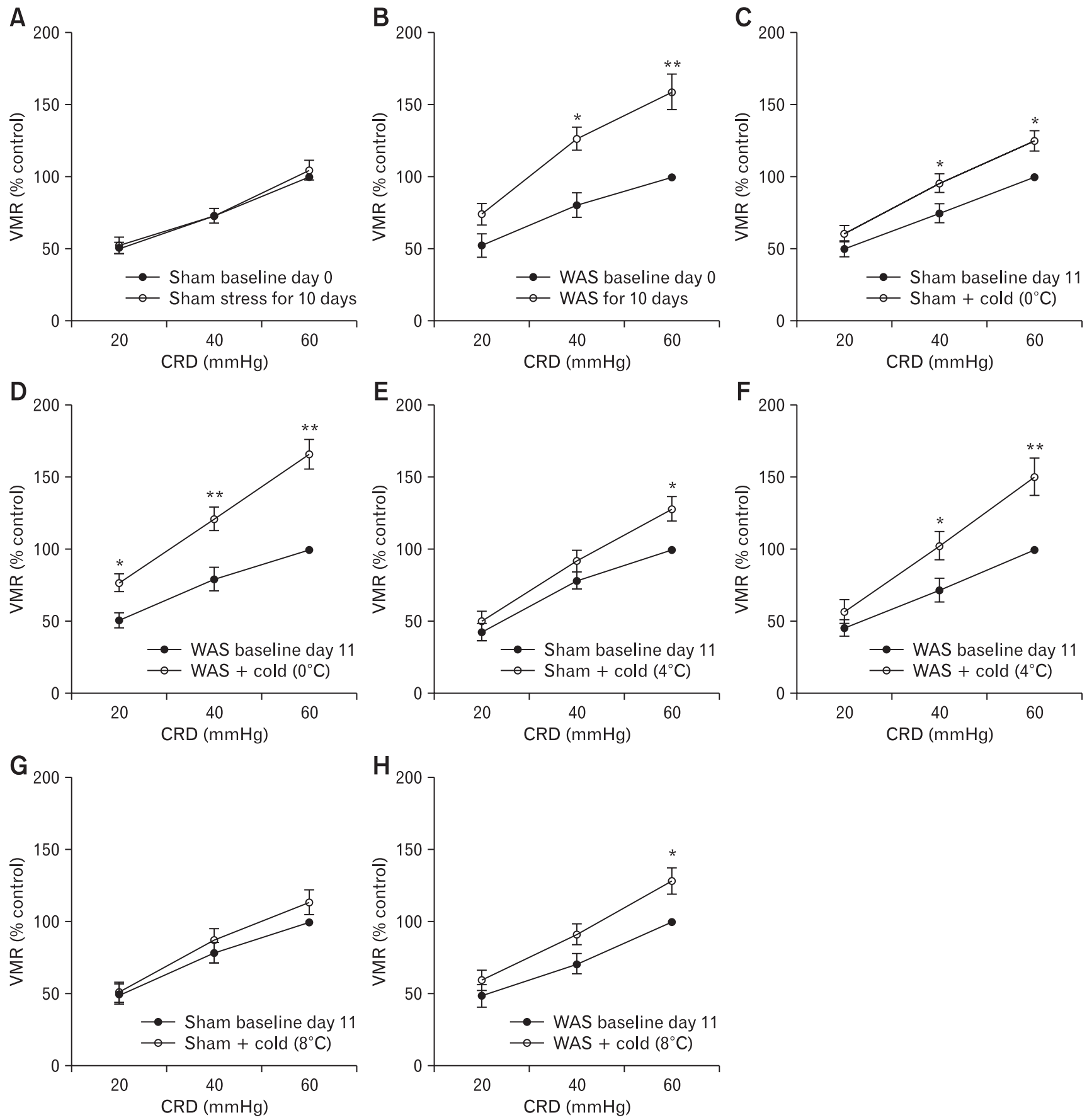

Figure 4. Chronic stress exacerbates cold-induced pronociception. (A) Effect of a 10-day sham stress on visceromotor response (VMR) to colorectal distention (CRD) in rats. (B) Effect of a 10-day water avoidance stress (WAS) on VMR to CRD in rats. (C, D) Effect of intra-antral infusion of saline at $0^{\circ} \mathrm{C}$ on the VMR to CRD in rats previously subjected to a 10-day sham stress or WAS. (E, F) Effect of intra-antral infusion of saline at $4^{\circ} \mathrm{C}$ on the VMR to CRD in rats previously subjected to sham stress or WAS. $(\mathrm{G}, \mathrm{H})$ Effect of intra-antral infusion of saline at $8^{\circ} \mathrm{C}$ on the VMR to CRD in rats previously subjected to sham stress or WAS. Data are expressed as mean \pm SEM of the VMR expressed as \% of $60 \mathrm{mmHg}$ response in the baseline set of $\mathrm{CRD}$ on day $0(\mathrm{~A}, \mathrm{~B})$ or day $11(\mathrm{C}-\mathrm{H}) .{ }^{*} \mathrm{P}<0.05,{ }^{*} \mathrm{P}<0.01(\mathrm{n}=6$ for sham stress groups and $\mathrm{n}=8$ for stress groups; 2-way ANOVA followed by Bonferroni post-test comparisons). 

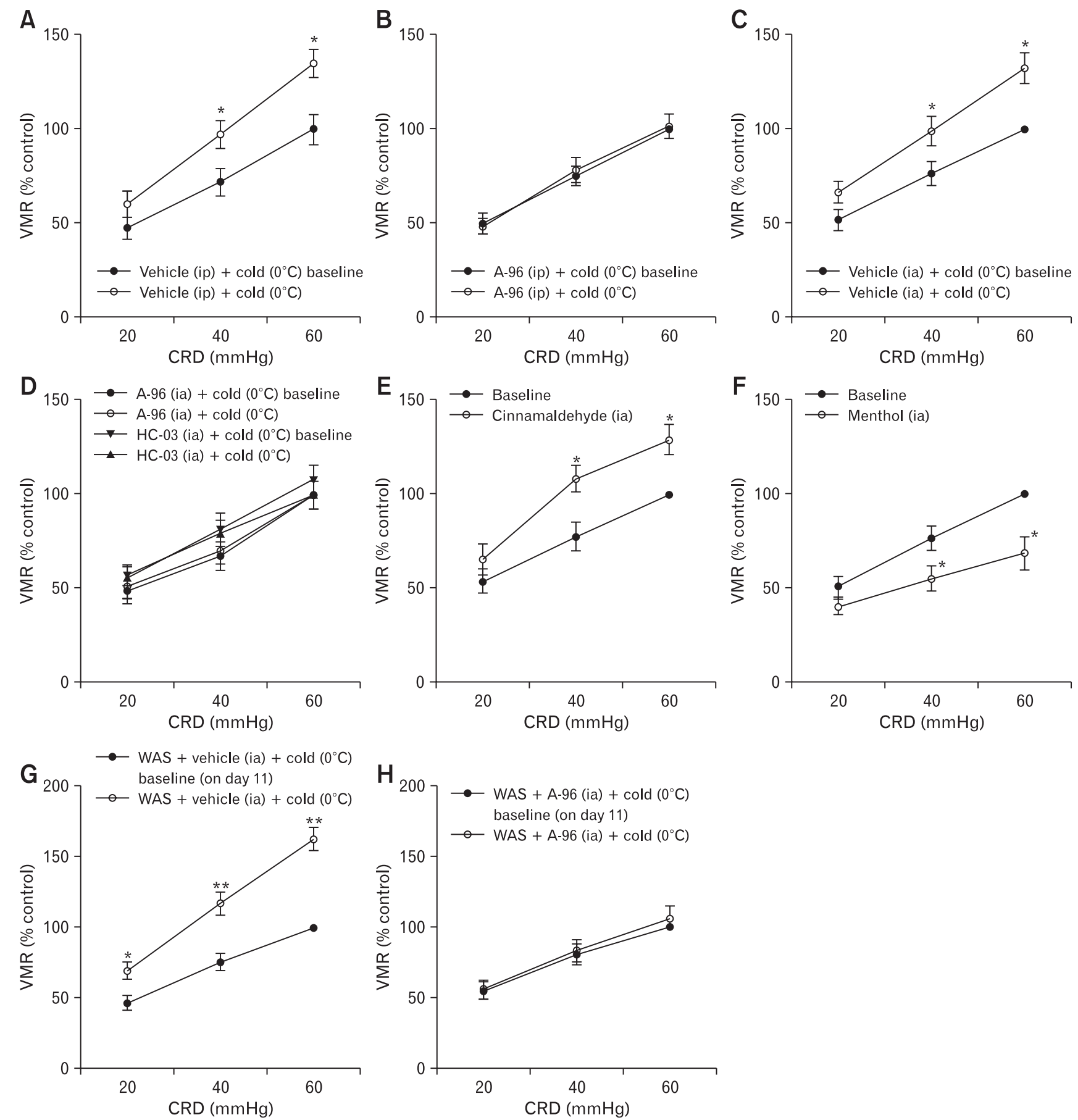

Figure 5. Cold-induced pronociception requires transient receptor potential ankyrin 1 (TRPA1) in rats. (A, C) Effect of intraperitoneally (ip) or intra-antrally (ia; $0.5 \mathrm{~mL}$ ) administered vehicle on visceromotor response (VMR) to colorectal distention (CRD). (B, D) A-967079 (A-96; 6 mg/ $\mathrm{kg}$, ip or $6 \mu \mathrm{g} / \mathrm{mL}$, ia) and $\mathrm{HC}-030031$ (HC-03; $1 \mathrm{mg} / \mathrm{mL}$, ia) attenuated the increase in the VMR to CRD after intra-antral infusion of saline at $0^{\circ} \mathrm{C}$. (E) Intra-antral infusion of cinnamaldehyde $(1.2 \mathrm{mg} / \mathrm{mL}, 0.5 \mathrm{~mL}$ ) increased the VMR to CRD. (F) Intra-antral infusion of L-menthol ( $4 \mathrm{mg} / \mathrm{mL}, 0.5 \mathrm{~mL}$ ) decreased the VMR to CRD. Data are expressed as mean \pm SEM of VMR expressed as $\%$ of $60 \mathrm{mmHg}$ response in the baseline set of CRD. $n=5-6$ naive rats per group. $(G, H)$ Intra-antral infusion of A-96 suppressed cold-induced pronociception in rats previously subjected to a 10-day water avoidance stress (WAS). Data are expressed as mean \pm SEM of VMR expressed as $\%$ of $60 \mathrm{mmHg}$ response in the baseline set of CRD on day 11. $\mathrm{n}=8$ per group. ${ }^{\star} P<0.05,{ }^{*} P<0.01$ (2-way ANOVA followed by Bonferroni post-test comparisons). 
to CRD after the cold saline infusion was not significantly different from baseline (Fig. 5B and 5D). A-967079, HC-030031, and vehicles (50\% and 10\% DMSO, respectively) alone did not affect the VMR to CRD (Supplementary Fig. 4). We also examined the effects of TRPA1 agonists on EMG activity. The CRD-evoked VMR significantly increased in rats receiving intra-antral administration of cinnamaldehyde compared to the baseline measurement $(P$ $<0.05$ at $40 \mathrm{mmHg}$ and $60 \mathrm{mmHg}$ pressures; Fig. 5E). Consistent with a previous report, ${ }^{27}$ the CRD-evoked VMR significantly decreased in rats infused with L-menthol, a TRPM8 agonist $(P<$ 0.05 at $40 \mathrm{mmHg}$ and $60 \mathrm{mmHg}$ pressures compared to baseline measurement; Fig. 5F).

We next tested the effect of TRPA1 antagonists on cold-
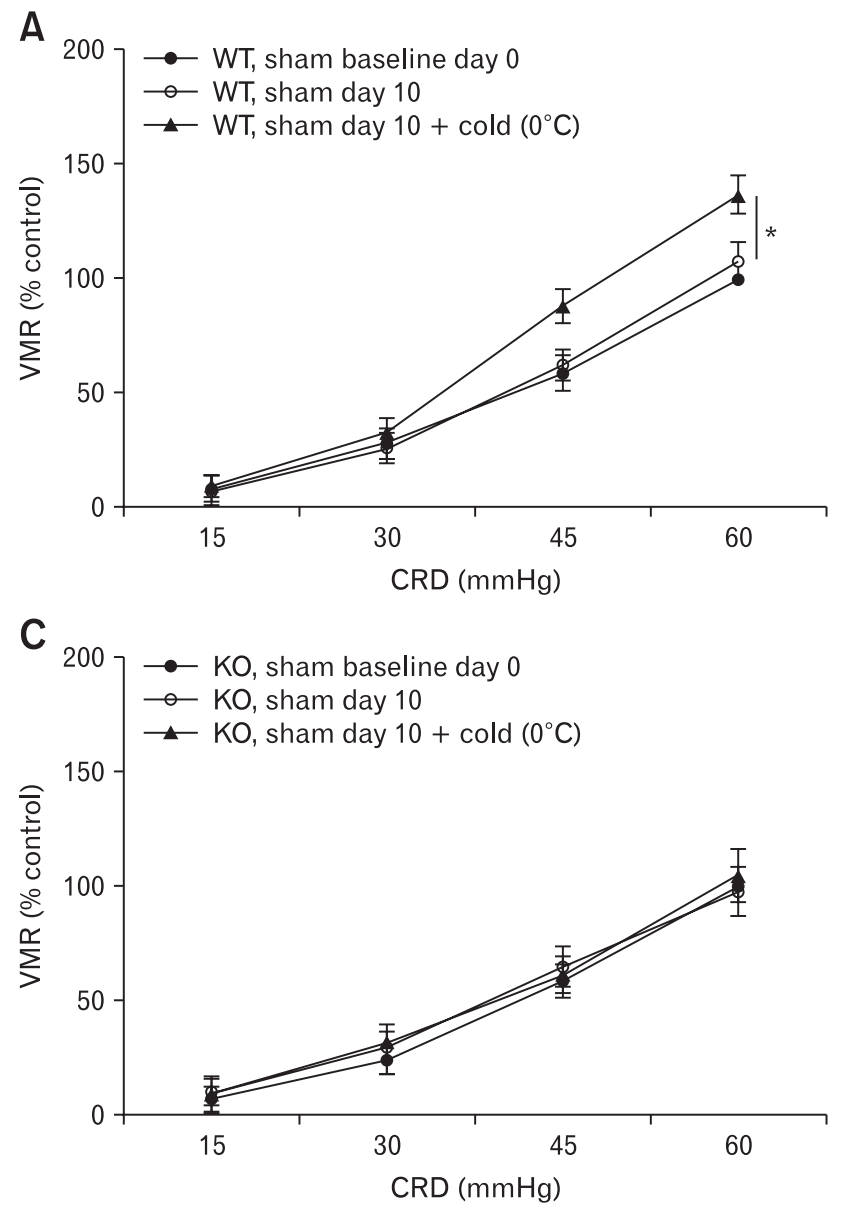

induced pronociceptive effect in stressed rats. Similar to the results of naive rats, pretreatment with A-967079 nearly abolished the increase in the VMR magnitude after cold saline infusion in rats previously subjected to a 10-day WAS (Fig. $5 \mathrm{G}$ and $5 \mathrm{H}$ ). To further confirm a functional role of TRPA1, we examined whether deleting the TRPA1 gene affects the behavioral response to cold stimulation under stressful conditions. TRPA $1^{-/}$mice and wild type mice were subjected to 9-day sham stress or WAS. The VMR to graded CRD was recorded on day 0 before the start of WAS and was termed baseline day 0 , which was similar in TRPA $1^{-/}$ mice and wild type mice (Supplementary Fig. 5A). On day 10, the VMR was recorded before infusion of cold saline and was denoted as sham day 10 or WAS day 10, which served as a baseline mea-
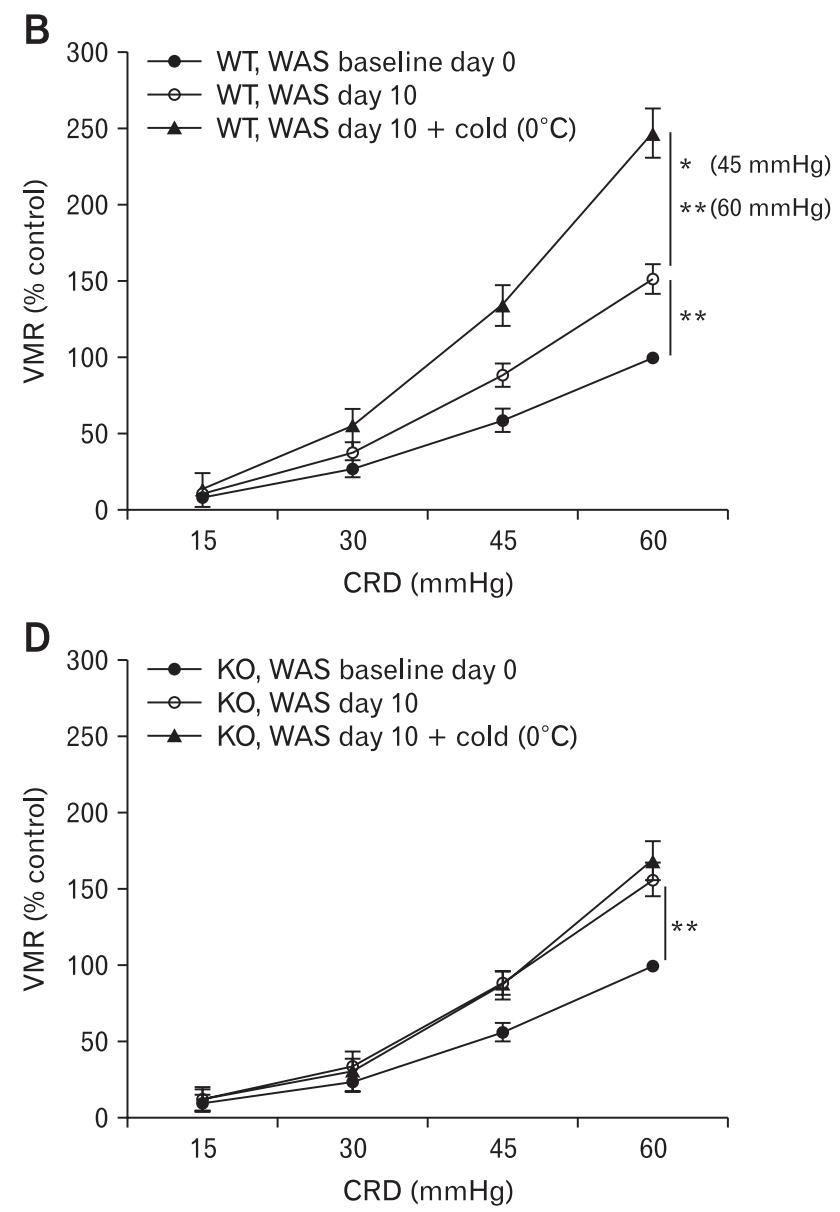

Figure 6. Deletion of transient receptor potential ankyrin 1 (TRPA1) gene abolished cold-induced pronociception in stressed mice. Effect of intra-antral infusion of saline $(0.2 \mathrm{~mL})$ at $0^{\circ} \mathrm{C}$ on visceromotor response (VMR) to colorectal distention (CRD) in wild type (WT) mice previously subjected to a 9-day sham stress (A) or water avoidance stress (WAS; B). Effect of intra-antral infusion of saline at $0^{\circ} \mathrm{C}$ on $\mathrm{VMR}$ to $\mathrm{CRD}$ in TRPA1 knockout (KO) mice previously subjected to sham stress (C) or WAS (D). Data are expressed as mean \pm SEM of VMR expressed as $\%$ of $60 \mathrm{mmHg}$ response in the baseline set of $\mathrm{CRD}$ on day $0 . \mathrm{n}=9-10$ per group. ${ }^{*} P<0.05,{ }^{*} \mathrm{P}<0.01$ at $\mathrm{CRD}$ pressures of $45 \mathrm{mmHg}$ and 60 $\mathrm{mmHg}$ (2-way ANOVA followed by Bonferroni post-test comparisons). 
surement for evaluation of the pronociceptive effect of antral cold stimulation. The VMR to CRD at pressures of $45 \mathrm{mmHg}$ and 60 $\mathrm{mmHg}$ was significantly greater in both wild type and TRPA $1^{-1-}$ groups subjected to WAS ( $P<0.01$ vs mice receiving sham stress; Supplementary Fig. 5B). In wild type mice previously subjected to a 9-day sham stress or WAS, the VMR to CRD at pressures of $45 \mathrm{mmHg}$ and $60 \mathrm{mmHg}$ increased significantly after cold saline infusion (sham stress: by $25.6 \pm 4.5 \%$ relative to sham day 10 level for pressure of $45 \mathrm{mmHg}$ and $29.0 \pm 5.2 \%$ relative to sham day 10 level for pressure of $60 \mathrm{mmHg}, P<0.05$; WAS: by $54.4 \pm 5.9 \%$ relative to WAS day 10 level for pressure of $45 \mathrm{mmHg}, P<0.05$ and $62.9 \pm 5.5 \%$ relative to WAS day 10 level for pressure of 60 mmHg, $P<0.01$; Fig. 6A and 6B). By contrast, in TRPA1 ${ }^{-/}$mice previously subjected to a 9-day sham stress or WAS, infusion of cold saline failed to elicit remarkable changes in VMR magnitude (sham stress: by $-2.6 \pm 3.9 \%$ relative to sham day 10 level for pressure of $45 \mathrm{mmHg}$ and $7.1 \pm 4.4 \%$ relative to sham day 10 level for pressure of $60 \mathrm{mmHg}$; WAS: by $-1.4 \pm 3.4 \%$ relative to WAS day 10 level for pressure of $45 \mathrm{mmHg}$ and $8.2 \pm 5.6 \%$ relative to WAS day 10 level for pressure of $60 \mathrm{mmHg}$, Fig. 6C and 6D).

\section{Expression of Transient Receptor Potential Ankyrin 1 in Vagal Afferents Is Increased in Rats Subjected to Chronic Stress}

In contrast to the sham stress group, rats subjected to WAS showed a significantly increased TRPA1 protein levels in nodose ganglia ( $P<0.01$; Fig. 7A and 7B). Consistently, TRPA1 (but not TRPV1) mRNA levels in the antral tissues significantly increased in stressed rats $(P<0.01$ vs sham stress group; Fig. 7C). The mRNA levels for TRPA1 and TRPV1 in T6-10 DRG of stressed rats were similar to those in sham stress rats (Fig. 7D).

We also examined gene expression of several inflammatory cytokines in antral tissues. As Figure 7E shows, quantitative PCR measured a significant increase in mRNA levels of TNF- $\alpha$, IL-1 $\beta$,
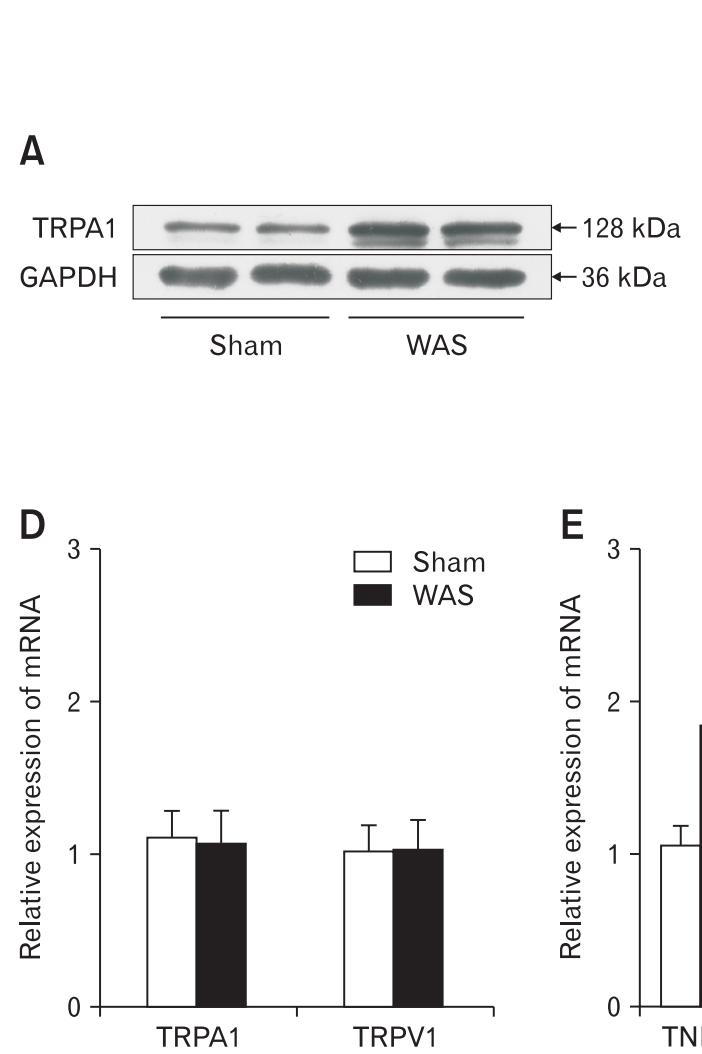
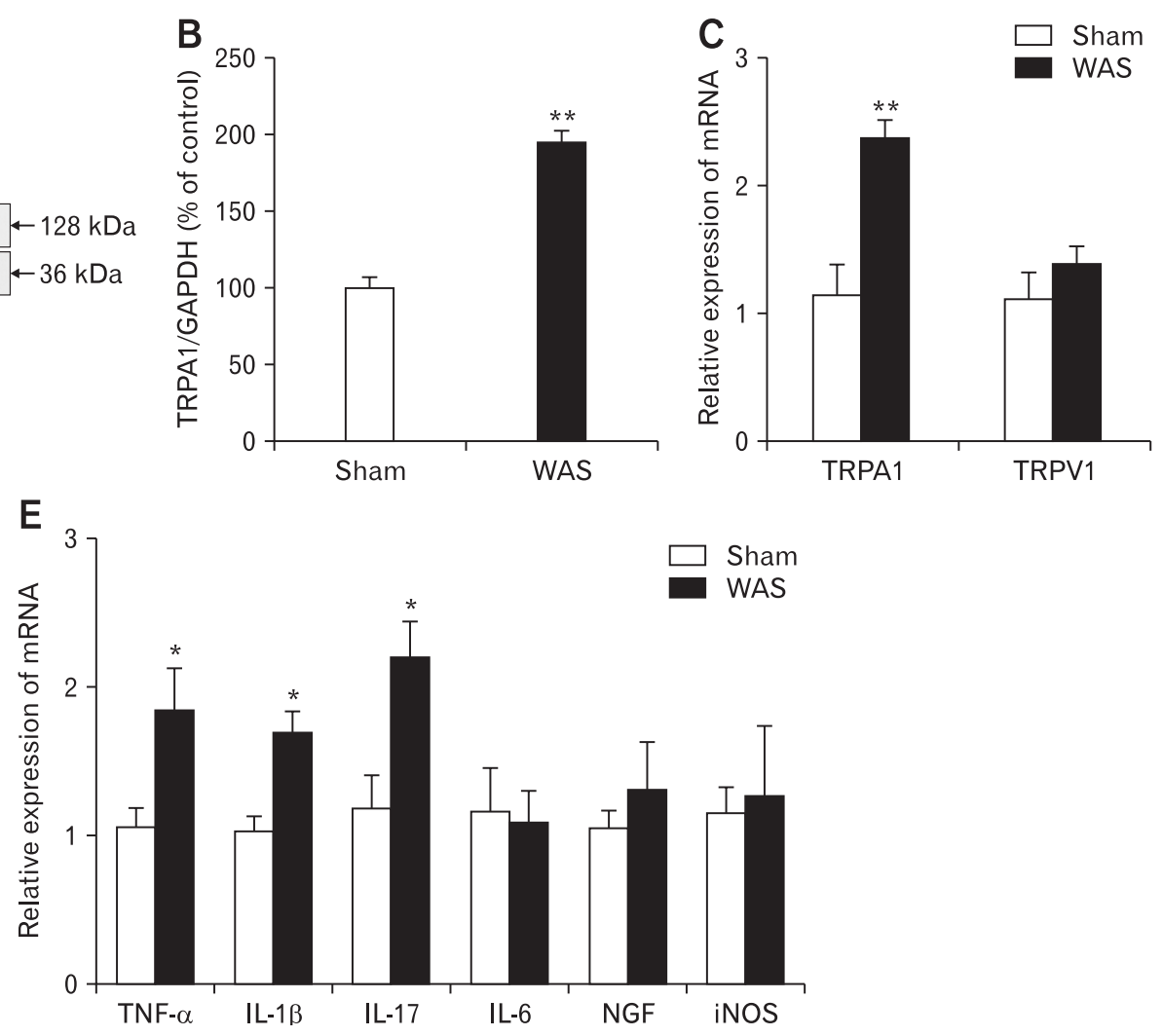

Figure 7. Chronic stress increases transient receptor potential ankyrin 1 (TRPA1) expression in vagal afferents. (A) Representative western blot bands showing increased TRPA1 protein levels in nodose ganglia of rats subjected to a 10-day water avoidance stress (WAS). (B) Expression levels were quantified using Image J software $(n=4)$. (C) TRPA1 mRNA levels in the antral tissues were increased in stressed rats $(n=8)$. $(D)$ TRPA1 mRNA levels in T6-10 dorsal root ganglia of stressed rats $(\mathrm{n}=8)$. (E) Effect of WAS on mRNA levels of inflammatory cytokines, nerve growth factor (NGF), and inducible nitric oxide synthase (iNOS) in rat antral tissues $(\mathrm{n}=8) .{ }^{*} P<0.05$, ** $P<0.01$ (Student's $t$ test). GAP$\mathrm{DH}$, glyceraldehyde-3-phosphate dehydrogenase. 
and IL-17 in stressed rats compared to sham stress rats $(P<0.05)$. No significant difference was measured in IL-6 mRNA level. We also detected the antral mRNA levels of NGF and iNOS, 2 inflammatory mediators, in stressed and control rats and found no obvious difference. Histological analysis revealed increased numbers of neutrophils and mononuclear cells in the lamina propria of the antral tissues from stressed rats $(P<0.05$ vs sham stress group; Supplementary Table 2), suggesting a low-grade antral mucosal inflammation after chronic stress.

We next examined whether gene deletion of TRPA1 could affect stress-induced antral inflammation. Similar to the results of experiments with rats, mRNA levels of TNF- $\alpha$ and IL-1 $\beta$ increased significantly in the antral tissues of wild type mice subjected to a 9-day WAS ( $P<0.05$ vs sham stress group). However, antral mRNA levels of these cytokines in TRPA $1^{-/}$mice subjected to WAS were not significantly different from those in sham stress TRPA1 $^{-/}$mice (Fig. 8)

\section{Transient Receptor Potential Ankyrin 1-dependent} Extracellular Signal-regulated Protein Kinase $1 / 2$ Activation in Nodose Neurons After Cold Stimulation Is Enhanced in Rats Subjected to Chronic Stress

We first examined p-ERK1/2 labeling in nodose neurons 10 minutes after antral infusion of cold saline in naive rats. We found few p-ERK1/2-labeled neurons in nodose ganglia from warm saline-infused rats. In contrast, a significantly larger proportion of nodose neurons were p-ERK1/2-labeled after cold saline infusion
( $P<0.01$ vs warm saline infusion; Fig. 9A). Pretreatment with A-967079 inhibited the cold-induced ERK1/2 phosphorylation in nodose neurons, with a significantly smaller proportion of $\mathrm{p}$ ERK1/2-labeled neurons after infusion of cold saline compared to that in rats receiving cold saline alone $(5.1 \pm 0.5 \%$ vs $11.8 \pm 1.2 \%$, $P<0.01$; Fig. 9B), suggesting that the cold-induced ERK1/2 activation is dependent on TRPA1. We then performed double staining of p-ERK1/2 and TRPA1 in nodose ganglia after infusion of cold saline. We found that $65.1 \pm 5.3 \%$ of $\mathrm{p}-\mathrm{ERK} 1 / 2$-positive neurons were also labeled with TRPA1 and $23.1 \pm 4.3 \%$ of TRPA1positive neurons were labeled with p-ERK1/2, whereas only 19.3 $\pm 1.8 \%$ of p-ERK1/2-positive nodose neurons were labeled with TRPM8 (Fig. 9C). The p-ERK1/2 labeling in DRG neurons after infusion of cold saline showed no significant difference from that after warm saline infusion (Supplementary Fig. 6).

Cold saline infusion also induced ERK1/2 activation in nodose neurons of rats subjected to WAS. Notably, the cold-induced ERK1/2 phosphorylation in nodose neurons was more robust in stressed rats, with a significantly higher proportion of $\mathrm{p}-\mathrm{ERK} 1 / 2$ positive neurons compared to that in sham stress rats $(24.8 \pm 1.8 \%$ vs $12.9 \pm 1.9 \%, P<0.01$; Fig. 10$)$.

\section{Transient Receptor Potential Ankyrin 1-dependent Calcium Influx in Nodose Neurons After Cold Stimulation Is Increased in Rats Subjected to Chronic Stress}

We then evaluated the relative changes in intracellular $\mathrm{Ca}^{2+}$ concentration upon cold stimulation in cultured nodose neurons by
A

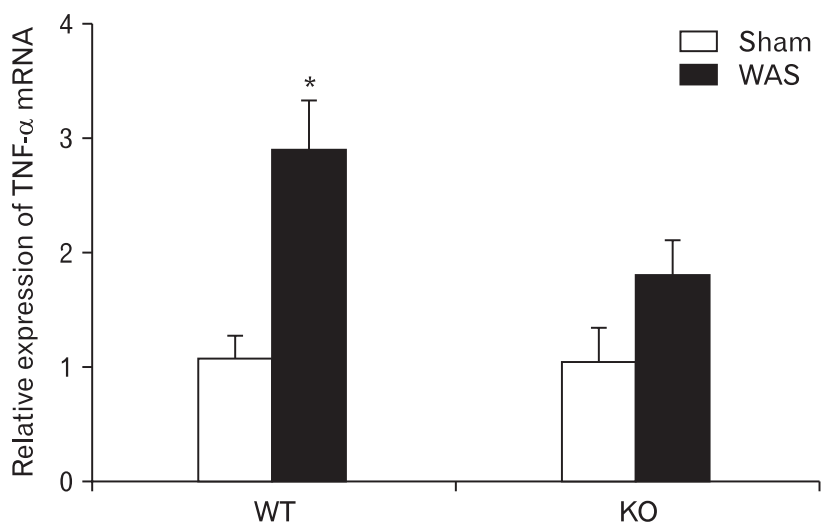

B

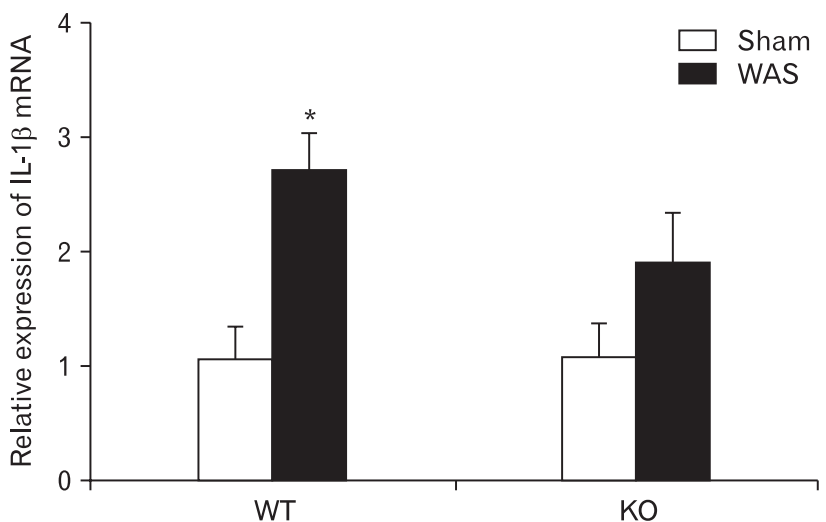

Figure 8. Effect of chronic stress on antral mRNA levels of TNF- $\alpha$ (A) and IL-1 $\beta$ (B) in wild type (WT) and transient receptor potential ankyrin 1 -knockout $\left(\mathrm{KO}\right.$; $\left.\mathrm{TRPA1}^{-/}\right)$mice $(\mathrm{n}=10)$. Antral tissues were obtained from WT and TRPA1 ${ }^{-/}$mice subjected to a 9-day water avoidance stress (WAS) and were analyzed with real-time quantitative polymerase chain reaction. The control groups received sham stress. ${ }^{*} P<0.05$ (Student's $t$ test). 

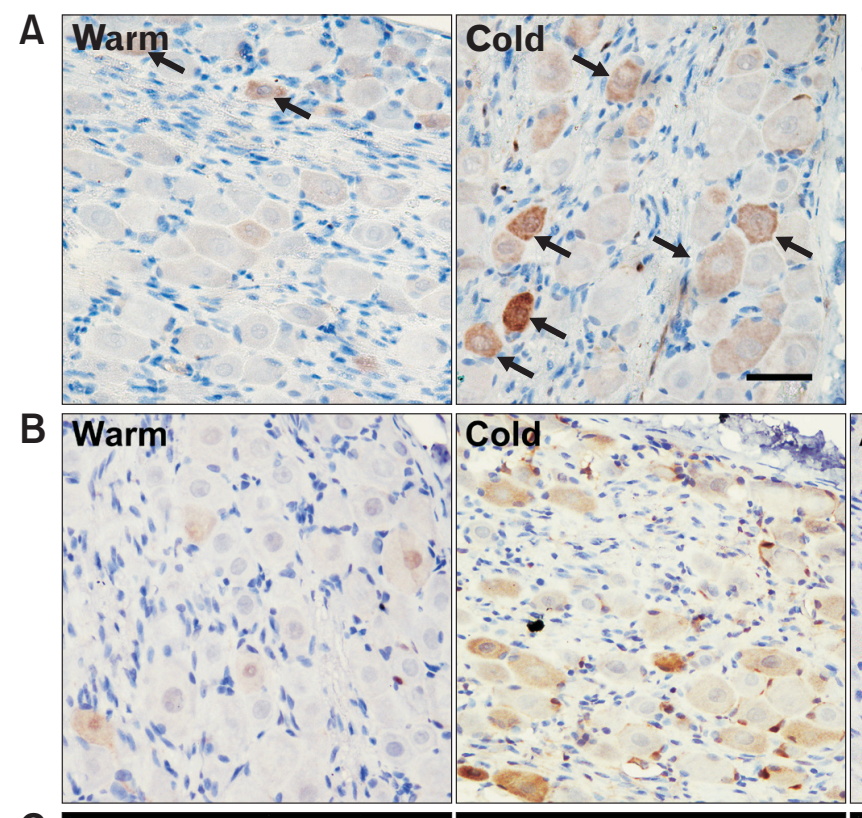

C
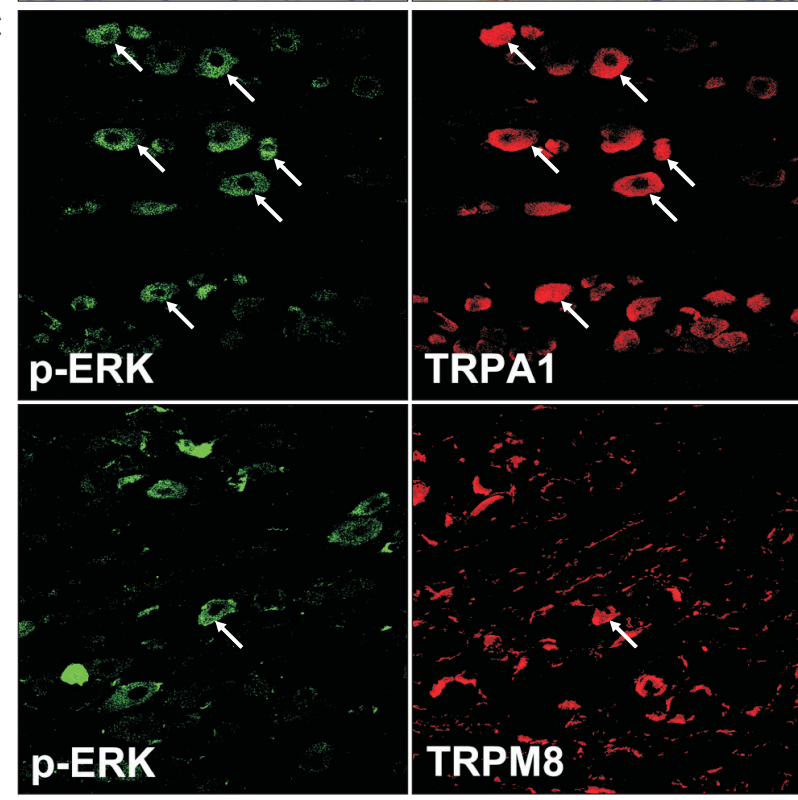

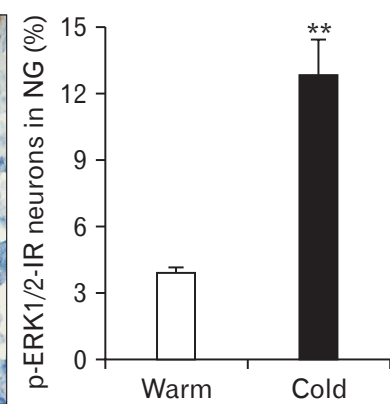

A-96 + cold
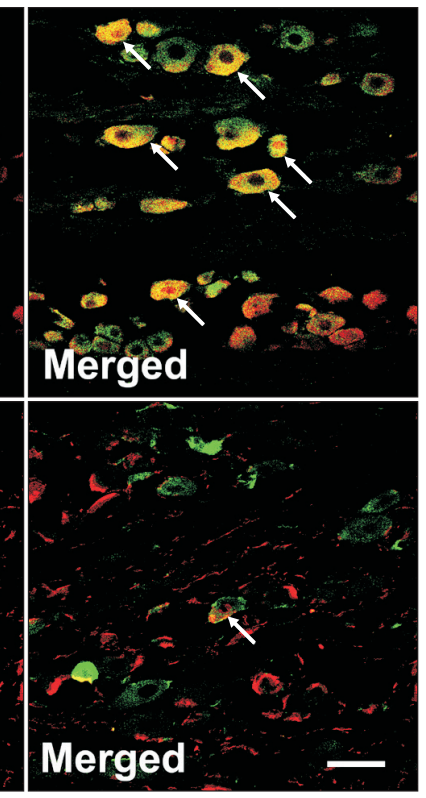

Figure 9. Transient receptor potential ankyrin 1 (TRPA1)-mediated extracellular signal-regulated protein kinase $1 / 2($ ERK 1/2) activation in nodose neurons after antral cold stimulation in naive rats. (A) Phospho-ERK1/2 (pERK 1/2) labeling in nodose neurons 10 minutes after intra-antral infusion of warm or cold $\left(0^{\circ} \mathrm{C}\right)$ saline. Arrows indicate p-ERK1/2-immunoreactive (IR) neurons. ${ }^{* *} P<0.01$ (Student's $t$ test). (B) A-967079 $(6 \mu \mathrm{g} / \mathrm{mL}$; intra-antrally administered) suppressed ERK1/2 activation in nodose neurons induced by antral cold stimulation. (C) Double labeling for TRPA1 or transient receptor potential melastatin 8 (TRPM8) and $\mathrm{p}-\mathrm{ERK} 1 / 2$ in nodose neurons after infusion of cold saline. Arrows indicate immunoreactive or double-labeled neurons. Scale bar $=100 \mu \mathrm{m}$. NG, nodose ganglia. calcium imaging. When the bath temperature was lowered from $35-36^{\circ} \mathrm{C}$ to about $12^{\circ} \mathrm{C}$, we measured a $122.0 \%$ increase over baseline in cytosolic $\mathrm{Ca}^{2+}$ mobilization in nodose neurons of naive rats $(P$ $<0.05)$; the proportion of neurons responding to cold stimulation was $57 \%(\mathrm{n}=45)$. In the neurons pretreated with A-967079, only a $4.7 \%$ increase over baseline in cytosolic $\mathrm{Ca}^{2+}$ mobilization was measured $(P<0.05$ vs cold treatment); whereas, pretreatment with $\mathrm{N}$-(3-Aminopropyl)-2-[(3-methylphenyl)methoxy]-N-(2-thienylmethyl) benzamide hydrochloride (AMTB), a TRPM8 inhibitor, did not affect the cold-induced calcium influx (Fig. 11A and 11B). In another experiment, when the bath temperature was lowered to about $12^{\circ} \mathrm{C}$, we measured a $136.6 \%$ increase over baseline in cytosolic $\mathrm{Ca}^{2+}$ mobilization in nodose neurons of sham stress rats and a significantly larger increase over baseline in nodose neurons of rats previously subjected to a 10 -day WAS (504.9\% over baseline, $P<$ 0.01 vs sham stress; Fig. $11 \mathrm{C}$ and 11D). The proportion of neurons responding to cold stimulation was $52.6 \%(\mathrm{n}=55)$ for sham stress rats and $70.7 \%(\mathrm{n}=41)$ for stressed rats. These results suggest that the cold-induced calcium influx in nodose neurons is dependent on TRPA1 (but not TRPM8) and that this effect is more robust under stressful conditions. 
A
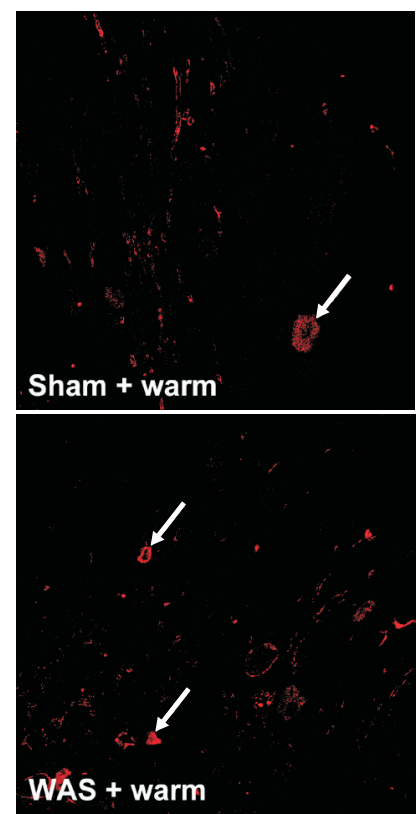
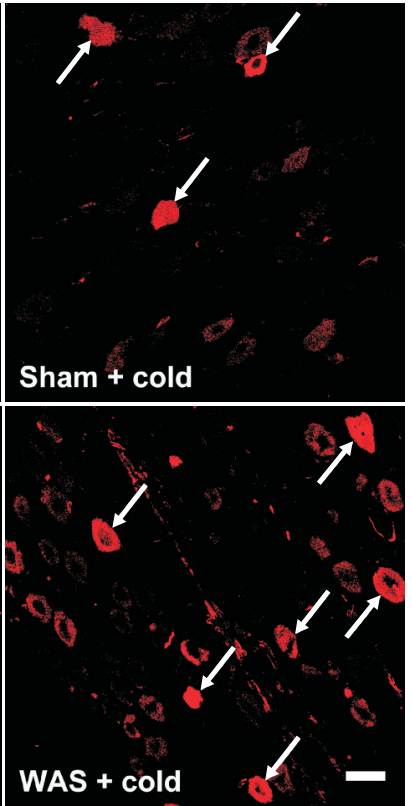

B

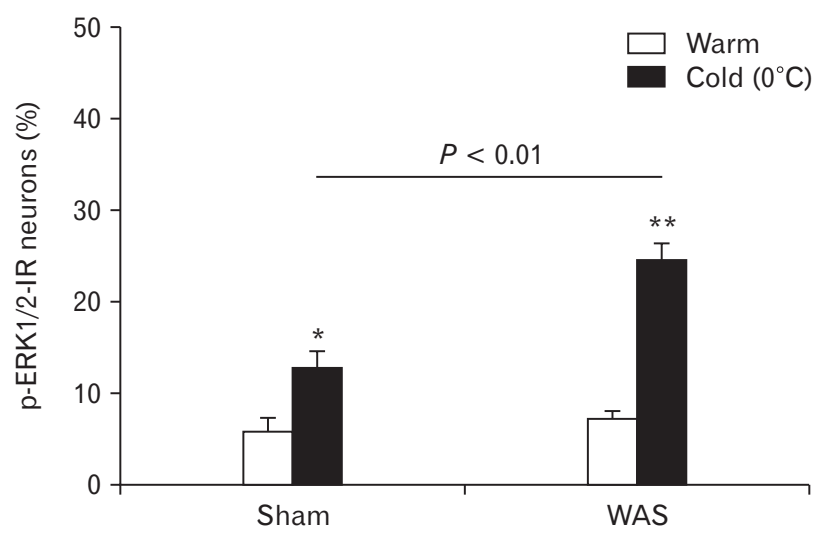

Figure 10. Chronic stress enhances extracellular signal-regulated protein kinase $1 / 2$ (ERK1/2) signaling in vagal afferents. (A) Phospho-ERK1/2 (p-ERK1/2) labeling in nodose neurons 10 minutes after intra-antral infusion of warm or cold $\left(0^{\circ} \mathrm{C}\right)$ saline in rats previously subjected to a 10 -day sham stress or water avoidance stress (WAS). Arrows indicate p-ERK1/2-immunoreactive (IR) neurons. Scale bar $=100 \mu \mathrm{m}$. (B) Proportions of p-ERK1/2-IR neurons in nodose ganglia after antral infusion of warm or cold saline in sham stress and stressed rats. ${ }^{*} P<0.05$, ** $P<0.01$ (Student's $t$ test).

\section{Discussion}

A variety of thermosensitive ion channels (such as TRPV1, TRPA1, and TRPM8) are expressed in vagal afferents innervating the upper GI tract. ${ }^{30}$ TRPA1 has been shown to mediate cold temperature sensing in mammalian vagal sensory neurons. ${ }^{11}$ In the present study, we observed that IBS-D patients exhibit elevated TRPA1 expression in the antral mucosa and that the latter was associated with abdominal symptoms after low-temperature exposure of the upper GI tract. Moreover, we demonstrate in an animal model system that antral cold stimulation causes vagal TRPA1dependent sensitization of visceral mechanonociception and that this effect is drastically potentiated upon stress.

Our clinical findings showing that antral TRPA1 levels in patients with IBS-D was increased and that antral TRPA1 mRNA levels positively correlated with abdominal symptoms after intake of cold water indicate a link between TRPA1 and abnormal GI cold sensing in IBS-D. These findings prompted us to explore the possible role of TRPA 1 in the low temperature-induced sensitization of visceral perception.

We observed in naive rats that antral cold exposure (via intraantral delivery of cold saline) caused increased visceral pain responses to CRD. This effect was accompanied with induction of cFos expression and ERK1/2 phosphorylation (which can activate c-Fos transcription ${ }^{31}$ ) in nodose (but not DRG) neurons and was abolished by perivagal application of capsaicin, which is used to functionally obliterate vagal afferents. ${ }^{14}$ Therefore, the cold-induced pronociceptive effect might depend on the capsaicin-sensitive vagal afferents.

We theorized that TRPA1 in vagal afferents mediates the response to antral cold stimulation based on the following observations. First, the majority of p-ERK1/2-immunoreactive nodose neurons of cold-treated rats also express TRPA1 (but not TRPM8), indicating that ERK1/2 activation after cold exposure is predominantly located in TRPA1-expressing vagal afferents. Second, pharmacological inhibition (whether systemic or local) of TRPA1 abrogated the cold-induced pronociception; and TRPA1 (but not TRMP8) agonists mimicked the response to cold exposure. Third, evidence shows that approximately $80 \%$ of nodose 
A

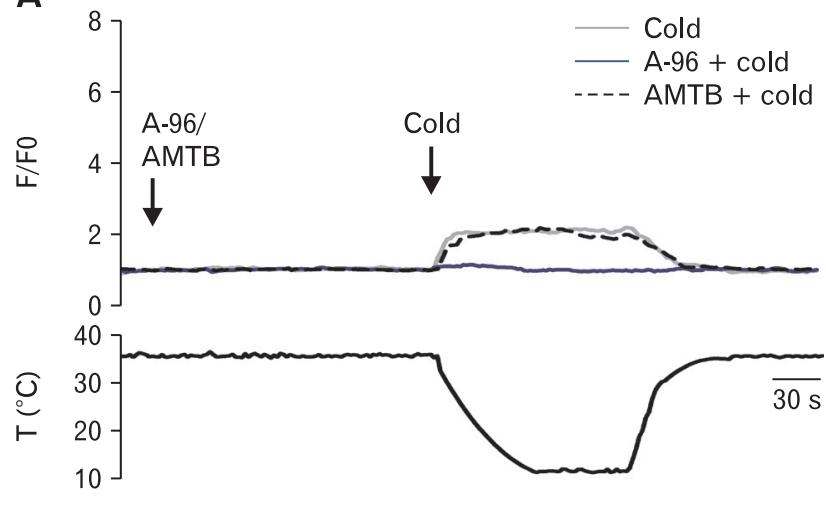

C

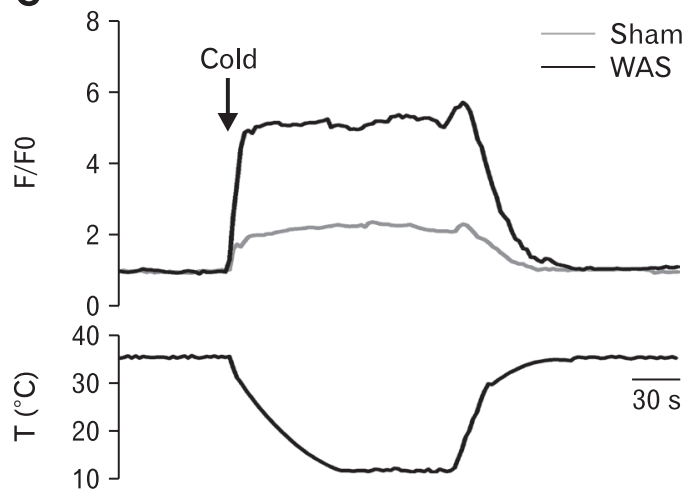

B

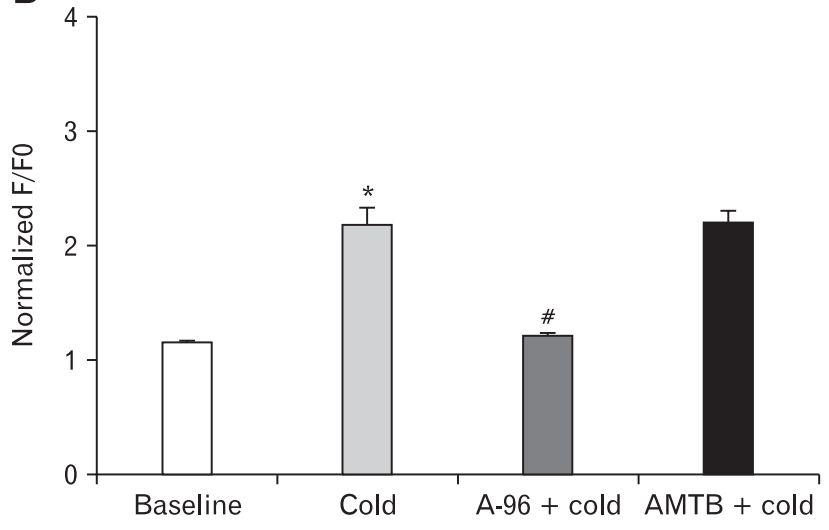

D

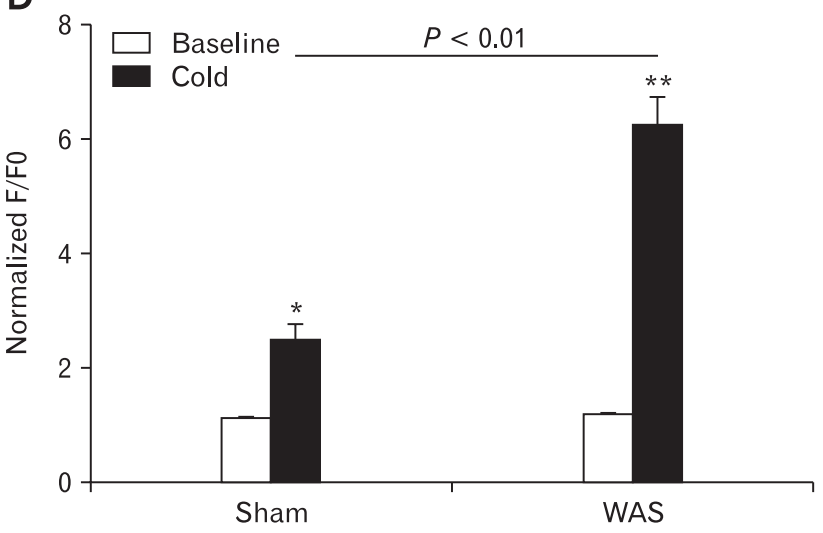

Figure 11. Transient receptor potential ankyrin 1 (TRPA1)-dependent calcium influx in cultured nodose neurons after cold stimulation is enhanced upon chronic stress. (A) Representative traces (top), bath temperature (bottom), and (B) the average values of peak amplitudes of calcium imaging in nodose neurons of naive rats during stimulation with cold temperature (about $12^{\circ} \mathrm{C}$ ) in the absence and presence of $\mathrm{A}-967079(5 \mu \mathrm{M})$ or N-(3-Aminopropyl)-2-[(3-methylphenyl)methoxy]-N-(2-thienylmethyl) benzamide hydrochloride (AMTB; $10 \mu \mathrm{M}) .{ }^{*} P<0.05$ vs baseline, ${ }^{\#} P<0.05$ vs cold (one-way ANOVA followed by Bonferroni post-test comparisons). (C) Representative traces (top), bath temperature (bottom), and (D) the average values of peak amplitudes of calcium imaging in nodose neurons of rats previously subjected to a 10-day water avoidance stress (WAS) or sham stress during cold stimulation. Data are expressed as F/F0 (ratio between basal fluorescence in the first 60 seconds and fluorescence at each time point; $\mathrm{n}=40$ cells). ${ }^{\star} P<0.05,{ }^{*} P<0.01$ (Student's $t$ test).

neurons co-express TRPA1 and TRPV1 while only approximately $15 \%$ of nodose neurons co-express TRPA1 and TRPM 8 and that TRPM8 and TRPA 1 could mark 2 different populations of cold-responsive neurons. ${ }^{18,26}$ Therefore, although TRPM8 is also cold-sensitive, it seems to be not involved in cold-induced visceral hypersensitivity. Notably, ERK1/2 phosphorylation in nodose neurons after cold stimulation was suppressed by a TRPA1 inhibitor, suggesting that cold-induced activation of vagal ERK1/2 signaling is dependent on TRPA1 and that ERK1/2 functions downstream of TRPA1 activation.

Abnormal brain-gut interactions upon stress are important pathophysiological components underlying the cardinal symptoms of IBS. ${ }^{2,32}$ We subsequently assessed the cold-evoked pronociception in an animal model of stress-induced visceral hypersensitivity and found that this effect was drastically potentiated, reflected by more pronounced enhancement of EMG activity upon cold stimulation and decreased noxious cold threshold temperature (Fig. 4). These results indicate an exaggerated pronociception when cold exposure is combined with prior psychological stress.

We then explored whether vagal TRPA1 is involved in the stress-exaggerated cold effect on visceral nociception. First, we observed that in stressed rats the cold-induced pronociception was nearly abolished by systemically or intra-antrally applied TRPA1 inhibitors. Consistently, gene deletion of TRPA1 also cancelled 
the cold-induced pronociception under stressful conditions. These findings indicate that the stress-enhanced pronociceptive effect of cold exposure requires TRPA1. Interestingly, TRPA1 has been implicated in the stress-induced visceral hypersensitivity. ${ }^{33}$ Our findings that $\mathrm{KO}+$ WAS mice showed the increased VMR response to $\mathrm{CRD}$ at $45 \mathrm{mmHg}$ and $60 \mathrm{mmHg}$ compared to the $\mathrm{KO}+$ sham group (Fig. 6B) indicate that WAS can aggravate the VMR response besides TRPA1 pathway. Second, the levels of TRPA1 protein and mRNA in nodose ganglia (but not T6-10 DRG) were overtly increased in stressed rats. These results indicate that TRPA1 in vagal afferent pathway could be involved in the stress-exacerbated visceral mechanonociception. Moreover, ERK1/2 activation in nodose neurons after cold stimulation in stressed rats was more prominent compared to sham stress rats, indicating an enhanced vagal ERK1/2 signaling upon stress. TRPA1 is a calcium-permeable ion channel and its activation allows calcium influx. ${ }^{11}$ Increases in intracellular calcium can induce ERK1/2 phosphorylation. ${ }^{34}$ We found that cold-evoked calcium influx, which is dependent on TRPA1 (but not TRPM8), was more robust in cultured nodose neurons of stressed rats. Therefore, our findings strongly imply that augmented vagal TRPA1 signaling contributes, at least in part, to the exaggeration of visceral mechanonociception following antral cold exposure under stressful conditions. The vagus nerve does not innervate the lower GI tract. It has been suggested that vagal afferents are involved in the descending modulation (inhibition or facilitation) of spinal nociceptive transmission. ${ }^{10,13,14,35}$ Therefore, the sensitization of visceral pain response to $\mathrm{CRD}$ after antral cold stimulation in stressed rats may be due to enhanced descending facilitation of spinal pain processing driven by augmented vagal TRPA1 signaling, rather than a direct modulation by vagal pathway.

The causes for the augmentation of vagal TRPA1 signaling are unclear. We observed a low-grade inflammation in the antral mucosa characterized by an increase in gene expression of cytokines (such as TNF- $\alpha$, IL- $1 \beta$, and IL-17) in stressed rats. It has been reported that inflammatory cytokines can induce TRPA 1 gene expression. ${ }^{36}$ Thus, it is possible that the upregulation of TRPA1 expression in stressed rats results from mucosal inflammation. Confusingly, we observed that gene deletion of TRPA1 repressed the stress-induced up-regulation of cytokine expression (Fig. 8), indicating that TRPA 1 could act as an upstream signal of cytokines under stressful conditions. Therefore, the mechanisms underlying the stress-induced TRPA1 expression needs further investigation. Collectively, our results imply that, under the stress-induced mucosal inflammatory condition, the upper GI mucosa is more sensitive to local cold temperature because of the augmented TRPA1 expres- sion and function in the vagal pathway, leading to sensitized visceral pain responses to $\mathrm{CRD}$.

The present study shows that visceral mechanonociception after gastric cold stimulation is drastically exacerbated upon stress. A possible explanation is that the upper GI mucosa is more sensitive to local cold temperature due to augmented vagal TRPA1 expression and function. The present study reveals a novel mechanism for the abnormal GI cold sensing and the resultant exaggeration of pain perception in IBS.

\section{Supplementary Materials}

Note: To access the supplementary tables and figures mentioned in this article, visit the online version of Journal of Neurogastroenterology and Motility at http://www.jnmjournal.org/, and at https://doi.org/10.5056/jnm19014.

Financial support: This work was supported by National Natural Science Foundation of China (Grant No. 81470812 and 81670484 to Shengliang Chen and Grant No. 81500412 to Xiujuan Yan).

\section{Conflicts of interest: None.}

Author contributions: Xin Chen and Qingqing Luo performed the experiments; Xiujuan Yan and Wenting Li analyzed the data; Shengliang Chen designed the research; and Xin Chen and Shengliang Chen wrote the paper. All authors approved the final version of the manuscript.

\section{References}

1. Farzaei MH, Bahramsoltani R, Abdollahi M, Rahimi R. The role of visceral hypersensitivity in irritable bowel syndrome: pharmacological targets and novel treatments. J Neurogastroenterol Motil 2016;22:558-574.

2. Drossman DA. Functional gastrointestinal disorders: history, pathophysiology, clinical features and Rome IV. Gastroenterology 2016;150:12621279, e2.

3. Zuo XL, Li YQ, Shi L, et al. Visceral hypersensitivity following cold water intake in subjects with irritable bowel syndrome. J Gastroenterol 2006;41:311-317.

4. Wang RF, Wang ZF, Ke MY, et al. Temperature can influence gastric accommodation and sensitivity in functional dyspepsia with epigastric pain syndrome. Dig Dis Sci 2013;58:2550-2555.

5. Vriens J, Nilius B, Voets T. Peripheral thermosensation in mammals. Nat Rev Neurosci 2014;15:573-589.

6. Karashima Y, Talavera K, Everaerts W, et al. TRPA1 acts as a cold sensor 
in vitro and in vivo. Proc Natl Acad Sci USA 2009;106:1273-1278.

7. Aubdool AA, Graepel R, Kodji X, et al. TRPA1 is essential for the vascular response to environmental cold exposure. Nat Commu 2014;5:5732.

8. Bautista DM, Jordt SE, Nikai T, et al. TRPA1 mediates the inflammatory actions of environmental irritants and proalgesic agents. Cell 2006;124:1269-1282.

9. Meseguer V, Alpizar YA, Luis E, et al. TRPA1 channels mediate acute neurogenic inflammation and pain produced by bacterial endotoxins. Nat Commun 2014;5:3125.

10. Grundy D. Neuroanatomy of visceral nociception: vagal and splanchnic afferent. Gut 2002;51(suppl 1):i2-i5 .

11. Fajardo O, Meseguer V, Belmonte C, Viana F. TRPA1 channels mediate cold temperature sensing in mammalian vagal sensory neurons: pharmacological and genetic evidence. J Neurosci 2008;28:7863-7875.

12. Lennerz JK, Dentsch C, Bernardini N, Hummel T, Neuhuber WL, Reeh PW. Electrophysiological characterization of vagal afferents relevant to mucosal nociception in the rat upper oesophagus. J Physiol 2007;582(Pt 1):229-242.

13. Chen SL, Wu XY, Cao ZJ, et al. Subdiaphragmatic vagal afferent nerves modulate visceral pain. Am J Physiol Gastrointest Liver Physiol 2008;294:G1441-G1449.

14. Wang EM, Li WT, Yan XJ, et al. Vagal afferent-dependent cholecystokinin modulation of visceral pain requires central amygdala NMDANR2B receptors in rats. Neurogastroenterol Motil 2015;27:1333-1343.

15. Blackshaw LA, Brierley SM, Hughes PA. TRP channels: new targets for visceral pain. Gut 2010;59:126-135.

16. Yang J, Li Y, Zuo X, Zhen Y, Yu Y, Gao L. Transient receptor potential ankyrin-1 participates in visceral hyperalgesia following experimental colitis. Neurosci Lett 2008;440:237-241.

17. Brierley SM, Hughes PA, Page AJ, et al. The ion channel TRPA1 is required for normal mechanosensation and is modulated by algesic stimuli. Gastroenterology 2009;137:2084-2095, e3.

18. Kondo T, Obata K, Miyoshi K, et al. Transient receptor potential A1 mediates gastric distention-induced visceral pain in rats. Gut 2009;58:13421352.

19. Brozmanova M, Ru F, Surdenikova L, Mazurova L, Taylor-Clark T, Kollarik M. Preferential activation of the vagal nodose nociceptive subtype by TRPA1 agonists in the guinea pig esophagus. Neurogastroenterol Motil 2011;23:e437-e445.

20. Hamilton M. The assessment of anxiety states by rating. Br J Med Psychol 1959;32:50-55.

21. Hamilton M. Development of a psychiatric rating scale for primary depression. Br J Soc Chin Psychol 1967;6:278-296.

22. Bradesi S, Schwetz I, Ennes HS, et al. Repeated exposure to water avoidance stress in rats: a new model for sustained visceral hyperalgesia. Am J
Physiol Gastrointest Liver Physiol 2005;289:G42-G53.

23. Ibeakanma C, Ochoa-Cortes F, Miranda-Morales M, et al. Brain-gut interactions increase peripheral nociceptive signaling in mice with postinfectious irritable bowel syndrome. Gastroenterology 2011;141:20982108, e5.

24. McGaraughty S, Chu KL, Perner RJ, Didomenico S, Kort ME, Kym PR. TRPA1 modulation of spontaneous and mechanically evoked firing of spinal neurons in uninjured, osteoarthritic, and inflamed rats. Mol Pain 2010;6:14.

25. Wei H, Koivisto A, Saarnilehto M, et al. Spinal transient receptor potential ankyrin 1 channel contributes to central pain hypersensitivity in various pathophysiological conditions in the rat. Pain 2011;152:582-591.

26. Bandell M, Story GM, Hwang SW, et al. Noxious cold ion channel TRPA1 is activated by pungent compounds and bradykinin. Neuron 2004;41:849-857.

27. Liu B, Fan L, Balakrishna S, Sui A, Morris JB, Jordt SE. TRPM8 is the principal mediator of menthol-induced analgesia of acute and inflammatory pain. Pain 2013;154:2169-2177.

28. Kimura Y, Mikami Y, Osumi K, Tsugane M, Oka J, Kimura H. Polysulfides are possible H2S-derived signaling molecules in rat brain. FASEB J 2013;27:2451-2457.

29. Sexton A, McDonald M, Cayla C, Thiemermann C, Ahluwalia A. 12-Lipoxygenase-derived eicosanoids protect against myocardial ischemia/reperfusion injury via activation of neuronal TRPV1. FASEB J 2007;21:2695-2703.

30. Yu X, Yu M, Liu Y, Yu S. TRP channel functions in the gastrointestinal tract. Semin Immunopathol 2016;38:385-396.

31. Price MA, Cruzalegui FH, Treisman R. The p38 and ERK MAP kinase pathways cooperate to activate ternary complex factors and c-fos transcription in response to UV light. EMBO J 1996;15:6552-6563.

32. Bennett EJ, Tennant CC, Piesse C, Badcock CA, Kellow JE. Level of chronic life stress predicts clinical outcome in irritable bowel syndrome. Gut 1998;43:256-261.

33. Chen J, Winston JH, Sarna SK. Neurological and cellular regulation of visceral hypersensitivity induced by chronic stress and colonic inflammation in rats. Neuroscience 2013;248:469-478.

34. Franklin RA, Atherfold PA, McCubrey JA. Calcium-induced ERK activation in human $\mathrm{T}$ lymphocytes occurs via $\mathrm{p} 56(\mathrm{Lck})$ and $\mathrm{CaM}-$ kinase. Mol Immunol 2000;37:675-683.

35. Ren K, Randich A, Gebhart GF. Effects of electrical stimulation of vagal afferents on spinothalamic tract cells in the rat. Pain 1991;44:311-319.

36. Hatano N, Itoh Y, Suzuki H, et al. Hypoxia-inducible factor-1alpha (HIF 1alpha) switches on transient receptor potential ankyrin repeat 1 (TRPA1) gene expression via a hypoxia response element-like motif to modulate cytokine release. J Biol Chem 2012;287:31962-31972. 